\title{
Paleoambientes y estratigrafía secuencial de depósitos marinos marginales del Ordovícico de la sierra de Zapla (sierras Subandinas, noroeste argentino) y su relación con la Cuenca Andina Central
}

\author{
Ricardo A. Astini
}

Larisa F. Marengo

\author{
Laboratorio de Análisis de Cuencas, Cátedra de Estratigrafía y Geología Histórica, \\ Facultad de Ciencias Exactas, Físicas y Naturales, Universidad Nacional de Córdoba,

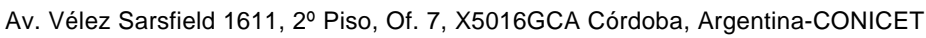 \\ raastini@com.uncor.edu
}

Centro de Investigación Paleobiológicas, Facultad de Ciencias Exactas, Físicas y Naturales, Universidad Nacional de Córdoba, Av. Vélez Sarsfield 299,X5000JJC, Córdoba, Argentina-CONICET Imarengo@efn.uncor.edu

El Ordovícico clástico de la sierra de Zapla (noroeste argentino), aunque sin base visible se encuentra excepcionalmente bien expuesto en el curso inferior del río Capillas (sierras Subandinas, Provincia de Jujuy). Desde un punto de vista paleontológico, el contenido de macrofaunas es pobre, debido a la escasez de ambientes marinos abiertos como lo indica el análisis paleoambiental, siendo el registro de palinomorfos una herramienta fundamental para establecer la posición estratigráfica de las unidades representadas, y las trazas fósiles presentes resultaron importantes en el análisis paleoambiental. A partir de un minucioso análisis de facies, arquitectura de los depósitos y delimitación de superficies diagnósticas se reconocieron cuatro secuencias depositacionales (S1-S4) con diferente desarrollo y compatibles con ciclos de 3er orden. La Formación Zanjón (parte superior de la Serie Global 2 y Serie Global 3) inicia la sección estratigráfica y está caracterizada por facies heterolíticas con alternancia de capas de tormenta con microconglomerados fosfáticos y pavimentos de braquiópodos linguliformes, comunes en llanuras de marea con frecuentes rasgos de exposición subaérea que incluyen ondulitas truncadas y grietas de contracción. En esta unidad se superponen las icnofacies de Skolithos y Cruziana. En transición gradual se desarrolla un intervalo profusamente bioturbado, con marcada coloración rojo-morada y desarrollo de bandas con intenso moteado (Miembro Laja Morada de la Formación Labrado). Éste representa una prolongada emersión (exposición subaérea) y actividad fluctuante de la capa freática en ambientes de interfluvio, durante una marcada caída relativa del nivel del mar ocurrida durante el Darriwiliano (Serie Global 4). En contacto neto y erosivo continua el Miembro Lagunilla de la Formación Labrado que marca un abrupto salto de facies y un relleno de canales fluvio-estuarinos con creciente dominio mareal. Una división interna tripartita permite caracterizar a este miembro como una sucesión estuarina transgresiva, con un particular desarrollo de la icnofacies de Glossifungites en sectores de interfluvios representando asociaciones típicas de sustratos endurecidos. La Formación Capillas (Darriwiliano alto y parte inferior de la Serie Global 5) se apoya en contacto neto y está representada por una cuña pelítica que gradualmente aumenta su proporción de arena hacia el tope. Ésta contiene los únicos indicadores de un ambiente marino franco con una valvifauna algo más desarrollada y concentrada en varias capas de tormenta desarrolladas por encima de la superficie transgresiva y en coincidencia con la superficie de máxima 
inundación y retracción de la línea de costa. Este es el único intervalo que puede con cierta precisión individualizarse en las depozonas de la Cordillera Oriental ubicada hacia el oeste y Bolivia. El gradual incremento de la fracción limosa y arenosa hacia el tope y el reemplazo de la icnofacies de Cruziana por una de tubos verticales (Skolithos) muy penetrativa, indica una gradual somerización y el pasaje a la Formación Centinela (parte media y superior de la Serie Global 5), donde se desarrollan paquetes arenosos cuarzosos en ambientes de mayor energía. Esto permite interpretar la progradación de un complejo deltaico que fue truncado por erosión en su tope. En contacto neto se sobrepone la Formación Zapla (Serie Global 6), asociada con el evento glacial hirnantiano (Ordovícico terminal), y registrada a lo largo de todos los Andes Centrales. Coronan la sección depósitos de plataforma fangosa asignados a la Formación Lipeón, de edad silúrica, y característicos de un período transgresivo posglacial al que se asocian mantos de hierro oolítico, sucedidos por planicies fangosas dominadas por trazas de Zoophycos.

\author{
Palabras claves: Paleoambientes, Estratigrafía secuencial, Ordovícico, Sierras Subandinas, Noroeste argentino, Cuenca Andina \\ Central.
}

\title{
ABSTRACT
}

Paleoenvironments and sequential stratigraphy of Ordovician marginal marine deposits of Sierra de Zapla (Sierras Subandinas, northwestern Argentina) and their relation with the Central Andean Basin. The best and most complete palynologically constrained Ordovician section across the Sierras Subandinas crops out in the southern part of the Sierra de Zapla along the Capillas River (Subandean Ranges, Jujuy Province). The dominantly marginal marine setting explains the scarcity of invertebrates throughout the section. Palynomorphs are the main tool in stratigraphic studies of the area and trace fossils are important aids in paleoenvironmental analysis. Based on a detailed facies analysis, geometry and paleocurrent analysis, and recognition of key surfaces, four depositional sequences (S1S4) with different internal arrangements and compatible with $3^{\text {rd }}$ order cycles were identified. The Zanjón Formation (upper part of Global Stage 2 and Global Stage 3) with unexposed base, initiates the stratigraphic section and it is characterized by a heterolithic facies association with subordinate storm layers, thin-bedded phosphate-rich micro-conglomerates and inarticulate-rich shell beds. Common subaerial exposure features like truncated ripple tops and mud cracks suggest tidal flat environments. This interval yields a mixed Skolithos-Cruziana ichnofacies. Towards the top, an increase in mottling and a gradual change into dominant purplish-red colors (Laja Morada Member of the Labrado Formation) indicate a protracted subaerial emergence during a Darriwilian (Global Stage 4) relative sea-level drop, and a fluctuating water table in interfluves. This unit is covered in sharp erosive boundary by the Lagunilla Member of the Labrado Formation, suggesting development of composite fluvial incisions. Sandy fluvial to tide-dominated estuarine fills and thoroughlybioturbated subtidal hetherolithic beds overlie the sequence boundary representing a typical transgressive systems tract. Development of surfaces with dominant Skolithos forms are interpreted as representing Glossifungites ichnofacies typically indicating by-pass erosion and firm-ground development previous to reworking of interfluves by advancing ravinement surface. The Capillas Formation (upper Darriwilian and lower part of Global Stage 5), sharply levels the previous estuarine complexes and represents a fine-grained wedge that gradually coarsens up. This unit contains the only truly marine shelly fauna concentrated in few storm beds above the fine-grained interval that characterizes a maximum flooding stage. This is the only interval that can be positively correlated with sections in the Cordillera Oriental to the west and Bolivia. A gradual coarsening to silty sandstones and the replacement of Cruziana by Skolithos dominated ichnofacies suggest a shallowing-upward section, capped by the thick-bedded, high energy quartz sandstones with pipe-rock structures of the Centinela Formation (middle and upper part of Global Stage 5). A shallowing-upward trend indicates the progradation of deltaic complexes, which in turn were erosively truncated by the waxing stage of the Gondwanan Hirnantian (uppermost Ordovician) ice-cap represented by the Zapla Formation (Global Stage 6) along the Central Andes. Above the diamictite-rich Zapla Formation the Lipeón Formation (Silurian) is interpreted as related to repeated transgressive ravinement surfaces that truncated $\mathrm{Fe}^{+2}$ saturated estuaries after a waning glacial stage and isostatic rebound, favouring the deposition of oolitic ironstones and succeeded by the development of a Zoophycos dominated muddy shelf. 


\section{INTRODUCCIÓN}

Depósitos ordovícicos se encuentran excelentemente expuestos en la Cuenca Andina Central, abarcando el noroeste de Argentina, Bolivia y Perú. Estaárea es considerada como una de las más espectaculares en el mundo para el estudio de las sucesiones ordovícicas gondwánicas, mostrando espesores mayores a los $5.000 \mathrm{~m}$ y exposiciones continuas a lo largo de decenas de kilómetros en las tres principales regiones morfoestructurales en que se divide (Puna, Cordillera Oriental y Sierras SubandinasSierras de Santa Bárbara) (Fig. 1). Asimismo, este registro se extiende hacia el subsuelo de la llanura Chaco-Paranaense donde se encuentra representado por menores espesores. Tradicionalmente, todas estas regiones fueron consideradas como cuencas separadas, principalmente por la influencia de la tectónica andina más reciente. De todos modos, no hay argumentos estratigráficos sustanciales para separar la historia sedimentaria ordovícica de estas provincias morfoestructurales. Durante este intervalo las diferencias estratigráficas y paleontológicas, como el desarrollo de discontinuidades, pueden ser explicadas sobre la base de la relativa continuidad de sistemas depositacionales a lo largo de una misma cuenca. Bahlburg $(1990,1991)$ fue el primero en sugerir una conexión entre los diferentes sistemas depositacionales del noroeste argentino con una perspectiva moderna. Recientemente, Astini (2003) involucró al conjunto dentro de un sistema encadenado de depozonas de antepaís, utilizando el modelo propuesto por DeCelles y Giles (1996).

Las sierras Subandinas, estudiadas originalmente por Bonarelli (1913), fueron divididas hacia el norte (Bolivia), en dos sectores diferentes sobre la base de su comportamiento estructural: el Subandino (s.str.) y el Interandino (Tröeng et al., 1993; Kley et al., 1996; Kley, 1996). Ramos (1999) extendió este concepto a los Andes de Argentina. La mejor sección para el estudio del Ordovícico clástico que allí se desarrolla, se encuentra a lo largo de una estructura anticlinal ubicada en la Provincia de Jujuy, denominada sierra de Zapla (Fig. 1).

El área de estudio del presente trabajo se encuentra sobre el río Capillas, el cual corta en sentido noreste-suroeste esta estructura anticlinal de $80 \mathrm{~km}$ de longitud, rumbo nornoroeste $\left(\mathrm{N} 30^{\circ} \mathrm{W}\right)$ e inmersión sur-sureste. En esta región afloran en forma casi continua, aunque sin base visible, algo más de $500 \mathrm{~m}$ de depósitos clásticos que abarcan desde el Ordovícico

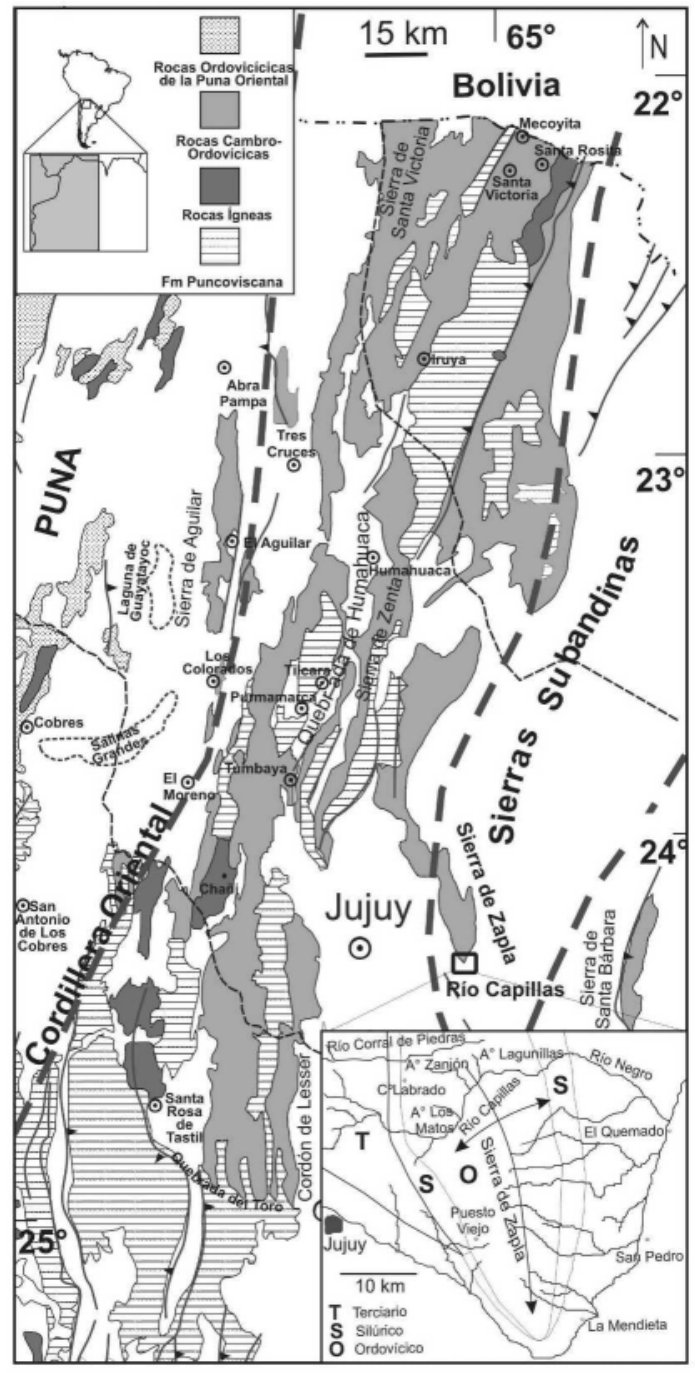

FIG. 1. Mapa de ubicación de la región de estudio y contexto regional (modificado de Astini, 2003).

Inferior alto (parte superior de la Serie Global 2) hasta el Ordovícico Superior (Serie Global 6) inclusive, y limitan en su techo con el Silúrico (Formación Lipeón; veáse Antelo, 1978). Este hecho la convierte en una de las únicas secciones estratigráficas del noroeste argentino donde el registro ordovícico inferior a superior, equivalente a la conocida Formación Acoite (Turner, 1960) de gran difusión en el ámbito de la Cordillera Oriental y unidades más jóvenes, es prácticamente continuo.

El objetivo de esta contribución es brindar un detallado análisis paleoambiental que permita esta- 
blecer una mejor vinculación de los depósitos ordovícicos de la región subandina con el resto de la cuenca andina central. Este análisis permite asimismo, discutir aspectos de la estratigrafía secuencial yestable- cer una curva relativa de fluctuaciones del nivel del mar que se propone como referencia para este segmento de la historia ordovícica en el noroeste argentino.

\section{ANTECEDENTES}

Si bien Harrington (en Harrington y Leanza, 1957) fue el primero en establecer nombres formales para la columna ordovícica de la sierra de Zapla, Monaldi et al. (1986) revisaron la estratigrafía y ordenaron las unidades litoestratigráficas de uso formal, como actualmente se las conoce.

Numerosos autores realizaron aportes en esta área de estudio. Schlagintweit (1943), definió el 'Horizonte Glacial de Zapla' de gran difusión en todo el noroeste argentino (Astini, 2002). Angelelli (1946) se ocupó de la geología y génesis del yacimiento ferrífero de Zapla. Cecioni (1949) agregó observaciones detalladas sobre el anticlinal. Finalmente, Nieniewskiy Wleklinski (1950) recopilaron muchos de los datos de los autores antes mencionados, discutieron la estratigrafía del anticlinal y construyeron el primer mapa escala 1:50.000 de la sierra de Zapla.

Los últimos estudios en la zona (Marengo y Astini, 2002; Astini y Marengo, 2003; Astini et al., 2003; Rubinstein, 2003a y b; Waisfeld y Henry, 2003; Sánchez et al., 2003) están referidos a los paleoambientes, edades y contenido faunístico de la sucesión ordovícica, así como la relación de esta columna con toda la cuenca ordovícica andina central. Una síntesis de estos aspectos fue publicada por Astini (2003). El presente trabajo sirve de base para la interpretación paleoambiental de las unidades y para establecer su arreglo estratigráfico.

De base a techo la estratigrafía de la región se compone por las siguiente unidades: Formación Zanjón (parte superior de la Serie Global 2 y Serie Global 3); Formación Labrado (Darriwiliano y Serie Global 4), dividida en Miembro Laja Morada y Miembro Lagunilla; Formación Capillas (Darriwiliano alto y parte inferior de la Serie Global 5); Formación Centinela (parte media y superior de la Serie Global 5) y Formación Zapla (Serie Global 6) (Fig. 2).

FIG. 2. Columna estratigráfica sintética aflorante sobre el río Capillas, sierra de Zapla. Se detallan las facies y asociaciones de facies. El número de cada facies coincide con la numeración del texto.

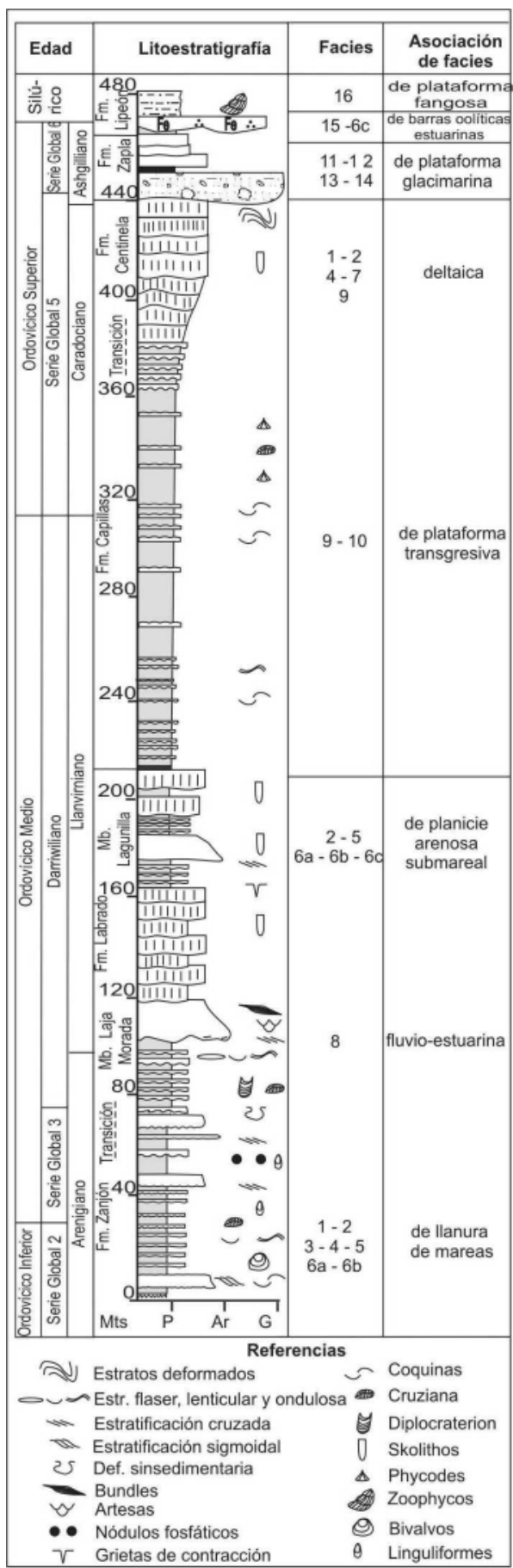




\section{METODOLOGÍA}

Se relevó el perfil geológico a lo largo del curso inferior del río Capillas y afloramientos de zonas adyacentes (arroyo Zanjón, arroyo Los Matos y curso superior del río Capillas) para la confección de una columna estratigráfica general (Figs. 1 y 2). La localización precisa de los puntos de la poligonal y de muestreo paleontológico se realizó con GPS. Las direcciones de paleocorrientes se tomaron en ondulitas de corriente y en estratificaciones cruzadas, utilizando la dirección de manteo. Adicionalmente, se plotearon frentes de barras, ejes de estructuras de corte y relleno y marcas de base lineales.

Las edades de las unidades fueron definidas en base a palinomorfos (Rubinstein, 2003a y b). Si bien en el área de estudio es utilizada tradicionalmente la nomenclatura de las antiguas Series británicas (véase Benedetto 2003 y trabajos allí citados), en este trabajo se aplica la nomenclatura de Series globales (figura 2) propuesta en Webby et al. (2004). Las muestras paleontológicas corresponden a concentraciones fosilíferas de la Formación Zanjón. Muestras de pelitas a lo largo de todo el perfil fueron extraídas para análisis micropalinológico. La mayoría de las trazas fósiles reconocidas provienen de la Formación Zanjón y Labrado, donde son más abundantes y están mejor preservadas.

En la primera parte de este trabajo, se analizan las facies, asociaciones de facies y contenido icnológico de la columna general, independientemente de la estratigrafía delárea. En la descripción einterpretación de las estructuras sedimentarias, se siguieron los lineamientos generales vertidos en Collinson y Thompson (1989) y Tucker (1998). Para la descripción de espesores se ha utilizado la terminología de Ingram (1954). Paralelamente a este análisis de facies, se estudiaron las asociaciones de trazas fósiles, determinando icnofacies para integrarestainformación con la anterior y así obtener una caracterización más acabada de los ambientes sedimentarios (Buatois et al., 2002). La segunda parte de esta contribución aborda el análisis paleoambiental de los depósitos de la sierra de Zapla, atendiendo a las unidades formacionales e integrando toda la información parala realización de un análisis estratigráfico secuencial.

\section{ANÁLISIS DE FACIES}

\section{FACIES HETEROLÍTICAS (FACIES 1)}

Esta facies es recurrente en los primeros $120 \mathrm{~m}$ de sección, más precisamente en la Formación Zanjón y el Miembro Laja Morada de la Formación Labrado.

Se trata de paquetes tabulares con estratofábrica delgada a muy delgada $(1 \mathrm{a} 10 \mathrm{~cm}$ ) y fina intercalación de areniscas grises con pelitas gris verdosas (Fig. 3A). La relación arena/pelita es variable siendo posible diferenciar los tres tipos clásicos de laminación flaser, lenticulary ondulada.

La subfacies lenticulary ondulada presenta contactos netos y una variada gama de patrones de ondulitas simétricas en sus topes. Entre las más comunes se desarrollan patrones con cierta asimetría y con crestas puntiagudas, con diseños rectos, bifurcaciones en ' $y$ ' griega, patrones romboidales y de interferencia. También son comunes las variedades truncadas, los patrones de microondulitas ('wrinkle marks') y ondulitas de adhesión.
Dentro de esta facies y con frecuencia afectando los intervalos pelíticos interpuestos entre trenes de ondulitas, se desarrollan grietas de contracciónque presentan una gran variedad de patrones y anchos (entre $\mathrm{mm}$ y $\mathrm{cm}$ ), siendo desde embrionarios (Fig. 3B), hasta triangulares, pentagonales y hexagonales, en ocasiones reemplazados con pseudomorfos de yeso y formando pavimentos agrietados. Además, pueden estar cortadas por trazas del tipo Skolithos (Fig. 3B). Interpretación. Lamarcadaritmicidad denota un patrón oscilatorio del flujo generador del depósito y la alternancia de procesos de decantación y tracción en el bajo régimen de flujo.

Los patrones de retrabajo de las subfacies lenticular y ondulosa, como ondulitas romboidales con cresta redondeada y ondulitas de interferencia, permiten inferir su desarrollo a poca profundidad (centímetros del pelo de agua) y bajo condiciones de flujos oscilatorios o multidireccionales. El principal agente generador habría sido el oleaje inducido por el viento. 

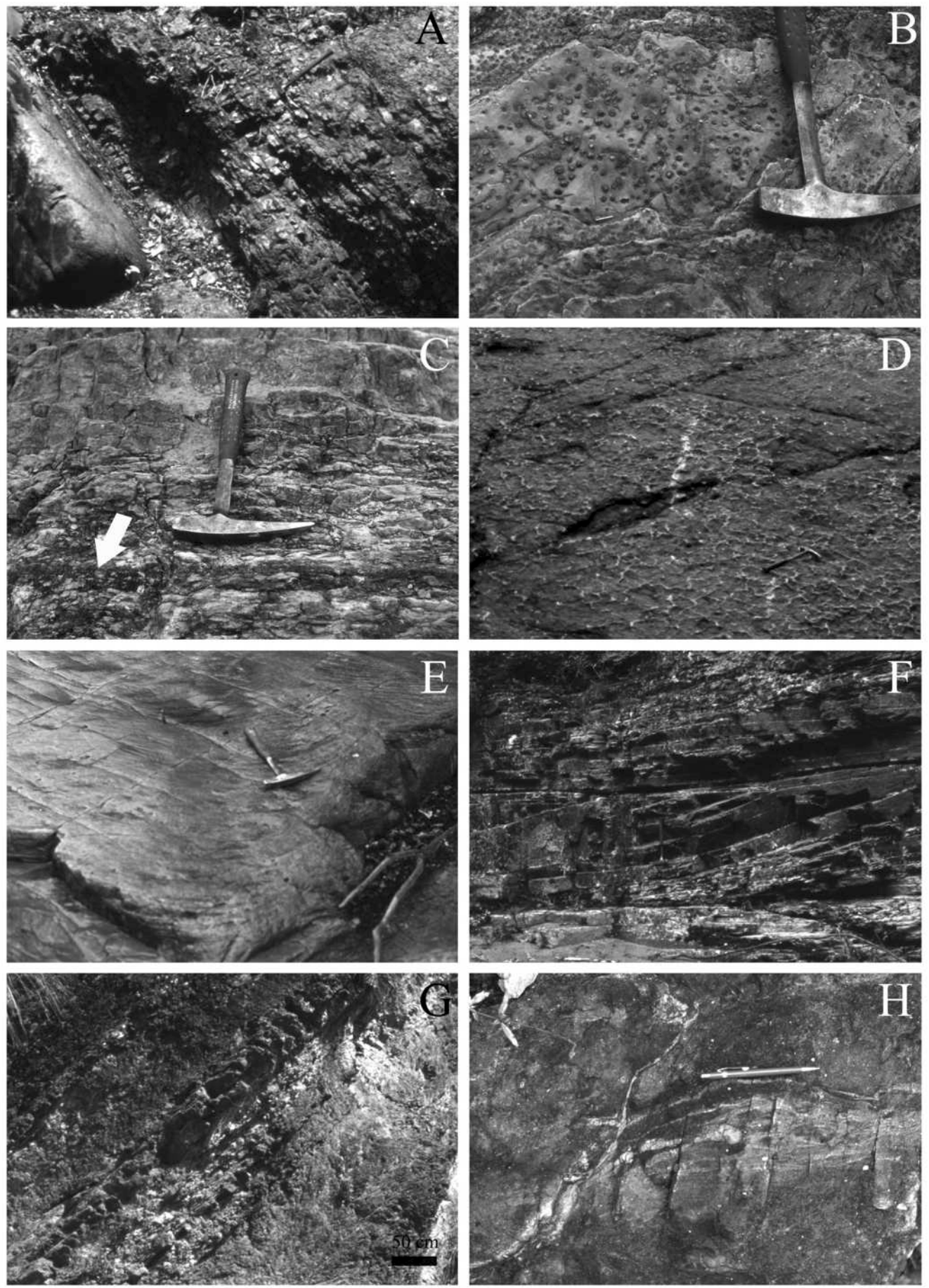

FIG. 3. A. Facies heterolíticas. Formación Zanjón; B. Facies heterolíticas. Tren de óndulas afectadas por grietas de sinéresis y cortadas por tubos de Skolithos. Formación Zanjón; C. Facies de microconglomerados fosfáticos. Formación Zanjón; D. Facies de fangolitas rojo-moradas con grietas de desecación. Miembro Laja Morada, Formación Labrado; E. Areniscas con estratificación cruzada (Facies 6). Mesoartesas. Miembro Lagunilla, Formación Labrado; F. Areniscas con estratificación cruzada tangencial (Facies 6). 'Tidal bundles'. Miembro Lagunilla, Formación Labrado; G. Facies de pelitas verdes con intercalaciones de areniscas tabulares gradadas. Formación Capillas; H. Facies de diamictita matriz soportada maciza. Formación Zapla. 
La exposición subaérea parcial está representada por las variedades truncadas (arrasamiento erosivo de sus crestas), ondulitas de adhesión y microondulitas, mientras que las grietas de desecación indican una exposición y desecación más prolongada. El conjunto de estas estructuras y fábricas heterolíticas en análogos modernos se desarrolla, con frecuencia en regiones intermareales de planicies de marea y planicies estuarinas (e.g., Allen, 1985).

En cuanto a las grietas de contracción con patrones embrionarios, pueden interpretarse como grietas de sinéresis, similares a las grietas de desecación pero originadas en el ambiente subácueo (Collinson y Thompson, 1989). Se interpretan como resultado de la pérdida del agua contenida en sustratos arcillosos como consecuencia de procesos de floculación diagenética temprana o por cambios de volumen inducidos por absorción diferencial de cationes durante variaciones de salinidad vinculadas con restricción paleoambiental (Collinson y Thompson, 1989). Debe destacarse que patrones de tubos verticales de Skolithos cortan a estas estructuras de contracción (Fig. 3B) a diferencia de lo que ocurre con las grietas de desecación. Las estructuras de desecación se asocian, en cambio, con ondulitas aplanadas y tapices con microondulitas y desarrollan una gran variedad de patrones y anchos. Estos últimos junto a los reemplazos con pseudomorfos de yeso implican exposiciones prolongadas y desecación completa. Las microondulitas aparecen junto a tapices microbiales en ambientes muy someros y tranquilos (Hagadorn y Bottjer, 1997) y en ocasiones se combinan con ondulitas de adhesión, que indican superficies húmedas con acción eólica.

\section{FACIES DE ARENISCAS FANGOSAS BIOTURBADAS (FACIES 2)}

En parte del Miembro Laja Morada y la sección superior del Miembro Lagunilla de la Formación Labrado, donde la traza fósil dominante es Diplocraterion, esta facies suele intercalarse con la facies 1.

Se trata de areniscas fangosas bioturbadas, de colores grises y con pobre diferenciación interna de las estructuras mecánicas. En general, esta facies se destaca por la dominancia casi exclusiva de un tipo de traza fósil, la que resulta tan penetrativa que impide apreciar estructuras primarias. En horizontes con mezcla incompleta y cierta 'transparencia' pueden observarse fábricas heterolíticas.
Interpretación. Se trataría de intervalos heterolíticos modificados (homogeneizados) por acción de la intensa bioturbación, a partir de organismos suspensívoros que habrían colonizado el fondo.

\section{FACIES DE MICROCONGLOMERADOS FOSFÁTICOS (FACIES 3)}

Esta facies se encuentra bien representada en la Formación Zanjón y el Miembro Laja Morada de la Formación Labrado, constituyendo niveles distintivos por su coloración oscura.

Se trata de delgados niveles de conglomerados finos con clastos de composición fosfática y bioclastos que aparecen con contactos netos y gradación normal, intercalados con la facies 1 . Lateralmente son discontinuos y pueden formar lentes de hasta $70 \mathrm{~cm}$ de espesor (Fig. 3C).

Internamente, poseen una fábrica bien condensada (clastosoportada en general) con clastos subredondeados de fosforita y areniscas fosfáticas y una alta fragmentación de los bioclastos. Localmente, se observan rasgos de bioturbación sobreimpuestos aumentando el porcentaje de finos intersticiales. La matriz es limo-arcillosa, aunque a veces participan gránulos de cuarzo, y el cemento es carbonático. Los bioclastos corresponden a fragmentos de braquiópodos linguliformes, según puede determinarse por la estructura interna laminar y el color pardo que se observa al microscopio, con extinción ondulosa en luz polarizada, característica del fosfato de calcio que compone sus valvas. Los clastos de areniscas fosfáticas están compuestos de granos de cuarzo finos, medianos y gruesos unidos por un cemento fosfático y calcita recristalizada.

Interpretación. Esta facies presenta características de acumulaciones condensadas (hiatales). Por su mezcla interna y grado de condensación mecánica, constituyen típicos depósitos retrabajados o que participaron de un prolongado proceso de reciclado y concentración. Föllmi et al. (1991) y Föllmi (1996) denominan este tipo de acumulaciones fosfatos alóctonos o transportados entendiéndolos como el resultado de períodos cortos de alta energía (e.g., tormentas), durante los cuales los depósitos primarios son expuestos en la interfase agua-sedimento, alterados y retransportados. Dichos autores sostienen que representan depósitos derivados del retrabajo de fosfatos autóctonos ('pristine phosphates') o fosfatos condensados ('condensed phosphates'). 
Algunas de las características de los fosfatos transportados son sus bases netas, la gradación interna y la mezcla de partículas fosfáticas con otro tipo de minerales como en este caso cuarzo y bioclastos. El alto grado de fragmentación de los bioclastos apoya, además, el carácter sedimentológico (sensu Kidwell et al., 1986) del depósito.

Si bien el origen primario del fósforo está en discusión, se proponen fuentes continentales alternativas a los surgimientos oceánicos ('upwelling'). Su aporte desde el continente ('continental runoff') y concentración inducida por productividad orgánica es común cuando la acumulación se produce en ámbitos relativamente restringidos como albúferas o sistemas estuarinos (Tucker, 2001). La aparición de abundantes linguliformes es coherente con esta hipótesis, ya que éstos indican ambientes de depositación con marcado estrés ambiental (variaciones de salinidad, temperatura y oxigenación del fondo) (Emig, 1997). Los sedimentos pelíticos son los que suelen contener a los fosfatos adsorbidos en forma de coloides, que particularmente se concentran durante etapas de escasa oxigenación durante la eodiagénesis. En los ambientes someros de plataforma su precipitación es inducida a partir de eventos de oxidación repentinos, que se vinculan con actividad de tormentas.

\section{FACIES DE ARENISCAS CON DEFORMACIÓN SINSEDIMENTARIA (FACIES 4)}

Esta facies se desarrolla en la transición del Miembro Laja Morada de la Formación Labrado con la unidad infrayacente (sobre el curso inferior del río Capillas) y en el arroyo Zanjón.

Son areniscas macizas afectadas por convoluciones y estructuras en almohadilla ('ball and pillow'). En los contactos con litologías más finas desarrollan calcos de carga de hasta $1 \mathrm{~m}$ de ancho y $0,5 \mathrm{~m}$ de amplitud. Internamente son homogéneas y desarrollan replegamiento interno. Ocasionalmente, los lóbulos arenosos se desprenden de la capa arenosa y constituyen estructuras en almohadilla. Estos lentes se encuentran aislados o rodeados por material fangoso.

Interpretación. El mecanismo de formación de estas estructuras está dado por flujo plástico inducido por gravedad, que actúa sobre capas de arena inconsolidadasyensituación inestable. Alserel material rápidamente depositado sobre un sustrato de composición contrastante, se produce una interdigitacióny consecuente deformación sinsedimentaria. En ambientes con altas tasas de sedimentación o sedimenta- ción súbita, como por ejemplo en facies de canal, constituyen rasgos comunes. Asimismo, su formación puede ser inducida por sismicidad.

\section{FACIES DE FANGOLITAS ROJO-MORADAS (FACIES 5)}

EstafaciesescaracterísticadelaFormación Labrado.

Se trata de fangolitas moradas a verdes con un elevado índice de bioturbación, evidenciado por abundantes moteados. El rasgo más destacado es la icnofábrica que alcanza índices de icnofábrica entre 4 y 6 (Droser y Bottjer, 1989), caracterizada por la destrucción de la laminación interna y fábrica primaria. Se presenta en bancos de hasta medio metro de espesor y buena continuidad lateral intercalada entre fangolitas arcillosas o en conjuntos amalgamados con contacto difuso entre capas. Desde el punto de vista textural, está compuesta por mezclas variables de fango y arena. Con respecto a la coloración, presenta la particularidad de no ser homogénea.

Son comunes los niveles con grietas de contracción por desecación, en el tope de las fangolitas. Las estructuras de contracción desarrollan profundidades variables de hasta $10 \mathrm{~cm}$ y anchos de hasta $2 \mathrm{~cm}$ y superposición de patrones regulares (triangulares, rectangulares, pentagonales) (Fig. 3D).

Interpretación. Las fangolitas constituyen mezclas texturales inducidas por bioturbación. La naturaleza primaria de la estratofábrica se desconoce pero por la existencia de relictos primarios y elevada proporción de fango, se interpreta que se habría tratado de facies heterolíticas, indicando niveles de energía bajos y períodos de gran actividad biogénica. Ocasionalmente, estos bancos habrían quedado semiexpuestos con la consecuente generación de pavimentos con grietas de contracción. Por otro lado, la coloración de las sedimentitas así como su textura moteada señalarían períodos de fluctuación de la capa freática.

\section{FACIES DE ARENISCAS CON ESTRATIFICACIÓN CRUZADA (FACIES 6)}

Esta facies está bien representada en el Miembro Lagunilla de la Formación Labrado.

Se trata de areniscas moradas y grises, donde es posible reconocer conjuntos de estratos ('cosets') amalgamados de hasta $15 \mathrm{~m}$ de espesor, que representan la superposición de formas de lecho de distinta escala. Engeneral, constituyen cuerpos con gradación normal. 
SUBFACIES DE ARENISCAS CON ESTRATIFICACIÓN CRUZADA DE MICROESCALA (SUBFACIES 6A)

Se trata de conjuntos de laminación cruzada (entre 3 y $5 \mathrm{~cm}$ de espesor) desarrollados en la parte superior de los bancos, con juegos de estratificación cruzada de mayor escala. Contiene variedades de laminación escalonada o ascendente, incluyendo formas en fase y fuera de fase. Las formas de lecho reconocidas en planta son trenes de ondulitas asimétricas con crestas continuas y sinuosas hasta linguoides. Asimismo, se observan patrones de ondulitas simétricas con crestas puntiagudas y valles cóncavos, ocasionalmente con desarrollo de topes truncados. En los valles también es frecuente el desarrollo de trenes de ondulitas de interferencia. A veces estos sectores están cortados, a su vez, por grietas de desecación y tubos verticales de Skolithos. Con menor frecuencia pueden observarse surcos epicniales constituidos por extensas trazas de Cruziana.

Interpretación. Los niveles con ondulitas de cresta asimétrica y diseños sinusoidales a linguoides y con crestas redondeadas son producto de corrientes unidireccionales en el bajo régimen de flujo. Los conjuntos con patrones escalonados reflejan altas tasas de sedimentación. En tanto, los patrones simétricos con crestas puntiagudas son producto de oleaje, en ocasiones con translación, hecho que queda reflejado en los patrones internos fuera de fase y desarrollo de ángulo de trepada. Los patrones de interferencia, al igual que las crestas arrasadas, indican muy escasa profundidad y hasta exposición subaérea. Estaúltima está acentuada por las grietas de desecación. Los tubos de Skolithos sobreimpuestos reflejan el asentamiento de comunidades suspensívoras previas a la exposición subaérea, aunque se han observado relaciones de corte inversas.

\section{SUBFACIES DE ARENISCAS CON ESTRATIFICA- CIÓN CRUZADA DE MESOESCALA (SUBFACIES 6B)}

Se trata de areniscas medianas a gruesas con conjuntos de estratificación cruzada planar, asintóticay en artesas de hasta $1,5 \mathrm{~m}$ de espesor individual, con ángulos de reposo de entre $25^{\circ}-35^{\circ}$ (Fig. 3E). En planta, ha sido posible reconocer la geometría de las formas de lecho, siendo las más comunes las de cresta sinuosa del tipo de las dunas (3D) y más raras las ondas de arena (2D). El ancho de las artesas varía entre
0,5 y $3 \mathrm{~m}$. Las paleocorrientes medidas indican sentidos predominantes hacia $260^{\circ}$ aunque, en menor medida, se desarrolla una moda secundaria con sentido opuesto que genera rosas bipolares. No se reconocieron patrones de estratificación espigada u ondulitas a contracorriente trepando sobre las caras de avalancha. Interpretación. Las dunas de tipo 2D y 3D reflejan condiciones de flujo unidireccional en la parte superior del bajo régimen, afectando arenas medias a gruesas. Estas formas se incluyen dentro del campo de las megaóndulas de los diagramas de Harms et al. (1982). Los cambios de espesor de los juegos de láminas cruzadas ('sets') son, en general, producto de etapas de erosión intermedias. Las variedades con terminaciones doblemente asintóticas indican ausencia de erosión. Aquellas con terminación angular indican una mayor tasa de movimiento de las formas de lecho y son comunes en ambientes con altas tasas de sedimentación. Las terminaciones asintóticas reflejan, en cambio, un tiempo de exposición más prolongado a los efectos de contraflujo, haciendo que las caras de avalancha sean más tendidas.

Las estructuras dominantes en esta subfacies, al igual que en la subfacies $6 a$, son comunes en canales y barras, en general.

\section{SUBFACIES DE ARENISCAS CON ESTRATIFICA- CIÓN CRUZADA DE MEGAESCALA (SUBFACIES 6C)}

Se trata de cuerpos lenticulares de areniscas medianas a gruesas con estratificación cruzada sigmoidal, con longitudes de onda del orden de la decena de metros y amplitudes del orden de 1 a $2 \mathrm{~m}$. Se midieron megartesas de hasta $20 \mathrm{~m}$ de ancho, compatibles con secciones transversales de barras. Internamente, muestran muy buen desarrollo de estratificación sigmoidal con particiones pelíticas y cubiertas de fango. En ocasiones, los conjuntos de bancos con estratificación sigmoidal llegan a tener hasta $15 \mathrm{~m}$ de espesor. Formas de lecho de meso y microescala se superponen comúnmente en las concavidades de los planos de estratificación cruzada sigmoidal, donde asimismo pueden aparecer acumulaciones bioclásticas de fósiles linguliformes muy fragmentados, a veces acompañadas de pequeños clastos fosfáticos. Las paleocorrientes predominantes indican sentido de este a oeste $\left(\sim 250^{\circ}\right.$ a $\left.300^{\circ}\right)$.

Los tapices pelíticos entre láminas o conjuntos de láminas poseen mejor preservación hacia la base de 
los conjuntos y se caracterizan por su agrupamiento cíclico (Fig. 3F).

Interpretación. La estratificación cruzada sigmoidal se asocia con migración de barras y bancos arenosos en ambientes poco profundos (submareales). Es probable que la acumulación de arenas esté favorecida por corrientes mareales que potencian la formación de paquetes mareales ('tidal bundles') que reflejan un avance cíclico de las formas de lecho (Kreisa y Moiola, 1986). Los tapices pelíticos se interpretan como pantallas de fango producto de decantación en los momentos de quietud entre mareas y son mejor preservados en la parte inferior de los juegos de laminas cruzadas afectados por menor erosión (Nio y Yang, 1991). Estas megaformas generalmente llevan sobreimpuestas otras estructuras sedimentarias de menor escala (cf. Boersma y Terwindt, 1981).

\section{FACIES DE ARENISCAS CUARZOSAS CON TUBOS VERTICALES (FACIES 7)}

Esta facies es recurrente dentro de la Formación Centinela.

Se trata de areniscas cuarzosas finas, medianas y gruesas, bien seleccionadas y de colores blanquecinos, dispuestas en bancos gruesos a muy gruesos, con tubos verticales en gran densidad, que le otorgan aspecto de empalizada y son conocidas en la literatura como 'pipe rocks' (Droser, 1991). Los tubos superan los $15 \mathrm{~cm}$ de largo y son asignables al icnogénero Skolithos. Una característica sobresaliente de esta facies es que en el afloramiento forma paredones resistentes a la erosión en los cuales es difícil individualizar la estratofábrica primaria debido a la intensa bioturbación.

Interpretación. La fábrica intensamente bioturbada y la baja icnodiversidad es común en ambientes litorales con energía moderada a alta y buena disponibilidad de nutrientes y en nuestro caso impide el reconocimiento de estructuras primarias diagnósticas. La profusión de tubos verticales es compatible con ambientes donde las condiciones de alta agitación posibilitan la presencia de abundantes partículas orgánicas en suspensión que determinan como tipo trófico dominante a los organismos suspensívoros (Pemberton etal., 1992a). Estos organismos habrían adoptado un hábito de vida infaunal para protegerse de la elevada energía del ambiente, construyendo estructuras que sirvieron de habitáculo más o menos permanente (e.g., Droser, 1991). La composición dominantemente cuarzosa de esta facies resulta compatible con un ambiente de elevada energía.

\section{FACIES DE ARENISCAS SABULÍTICAS MACIZAS (FACIES 8)}

Esta facies es recurrente dentro de la Formación Labrado tanto en el flanco occidental como en el flanco oriental del anticlinal de Zapla.

Se trata de areniscas sabulíticas que rápidamente pasan a areniscas medianas grises y desarrollan en algunossectoresestratificacióncruzadagrosera. Labase delos estratos es muy irregularyerosiva, desarrollando superficies de corte y relleno ('gutters') con perfiles en $\mathrm{V}$, aproximadamente simétricos y bien marcados, de hasta $1 \mathrm{~m}$ de extensión lateral y $0,3 \mathrm{~m}$ de profundidad. Interpretación. La facies 8 está vinculada a flujos canalizados de alto régimen. El carácter sabulítico del grano contrasta ampliamente con el tamaño de grano supra e infrayacente, además de poseer menor selección y madurez mineralógica, por lo que se infiere un cambio marcado en las condiciones del medio sedimentario asociado a un intervalo erosivo.

\section{FACIES DE PELITAS VERDES (FACIES 9)}

Esta facies es característica de la sección inferiory media de la Formación Capillas.

Se trata de fangolitas limo-arcillosas grises verdosas, que se encuentran intercaladas con la facies 10 (Fig. 3G). La estratificación es delgada a muy delgada y los bancos individuales presentan buena continuidad lateral. Ocasionalmente, se preserva estratificación lenticular, donde se destacan lentes areno-limosos.

Dentro de estafacies resaltan nivelestabulares, más arenosos, con abundantes Phycodes, las cuales borran todotipo deestructuras. Enalgunossectores, no obstante, puedendiferenciarseejemplares relícticos de Cruziana.

Interpretación. Estos depósitos resultan de un predominio de procesos de decantación en ambientes 'tranquilos' por debajo del tren de oleaje, aunque los esporádicos niveles heterolíticos indican una cierta influencia del oleaje.

\section{FACIES DE ARENISCAS TABULARES GRADADAS (FACIES 10)}

Esta facies es característica de la Formación Capillas. Se trata de estratos de areniscas delgados, continuos y tabulares, que resaltan muy bien en el afloramiento por alternar con las pelitas de la facies 9 (Fig. 3G). Tienen base neta y gradación normal. Las estructuras más representativas son laminación paralela, ondulíticay raros retrabajos por trenes de ondulitas simétricas en los topes. Ocasionalmente aparecen 
niveles con concentraciones bioclásticas, con fábricas abiertas ('shelter') y geopetales, portadoras de restos de bivalvos (Zaplaella gen.nov., Sánchez et al., 2003) y trilobites (Huemacaspis y Hoekaspis n.sp., Waisfeld y Henry, 2003).

Interpretación. Estos intervalos arenosos gradados pueden vincularse conflujos desacelerantes originados por la acción de tormentas. Sin embargo estructuras en domo y cuenco no fueron observadas. Tanto la gradación como la secuencia de estructuras y la presencia de saltuarias coquinas en labase son comunes de capas de tormentae indican una disminución gradual entre el alto y el bajo régimen de flujo. La participación de retrabajos de oleaje en el tope indica que, en general, fueron afectadas por la base del tren de oleaje de tiempo normal. Las bajas relaciones de arenisca/pelita de esta facies en relación a la facies 9 , la tabularidad de los estratos y ocurrencia de concentraciones bioclásticas indican que se trataría de depósitos de tormenta.

\section{FACIES DE DIAMICTITA MATRIZ SOPORTADA MACIZA (FACIES 11)}

Esta facies aparece en la Formación Zapla. Regionalmente, se dispone en contacto neto sobre areniscas blanquecinas de la Formación Centinela, aunque localmente apoya sobre facies más finas.

Se trata de una fangolita guijosa de color gris oscuro (pardusco en caras meteorizadas) con bloques suspendidos y frecuentes lentes de areniscas cuarzosas. Su aspecto de campo es macizo con estratofábrica mal desarrollada. El espesor de esta facies llega a tener 18 m en el flanco occidental del anticlinal de Zapla (próximo a la desembocadura del arroyo Los Matos en el curso superior del río Capillas) (Fig. 1). En la margen izquierda del curso inferior del río Capillas, y a $5 \mathrm{~m}$ de la base, se hallaron clastos subredondeados, facetados, pulidos y estriados de lamprófiros y areniscas verdes.

Texturalmente la diamictita es macizay tieneclastos de variada composición, pero mayoritariamente de granitos yareniscas cuarcíticas. Los cuerpos cuarcíticos tienen ancho y espesor variable e internamente están deformados, mostrando replegamientos de la laminación primaria (Fig. $3 \mathrm{H}$ ).

Desde un punto de vista petrográfico se trata de una grauvaca cuarzosa con parches cuarzo-líticos, es decir de areniscas fangosas con abundante matriz arcillo-limosa de soporte entre los granos, que son dominantemente cuarzosos. Su textura es polimodal y los granos de cuarzo son redondeados a subredondeadosy, en general, monocristalinos. Ocasionalmen- te, presentan caras fragmentadas (cóncavas) y hábitos aciculares. Los litoclastos son de rocas pelíticas y excepcionalmente se observan gránulos que podrían pertenecer a rocas graníticas.

Interpretación. Se interpretan como depósitos gravitacionales dominantemente cohesivos (Postma, 1986). Posiblemente deriven de flujos de detritos con dinámica interna laminary depositación en masa. Esto último explica el aspecto macizo. Esta facies es comparable con las Dmm de Eyles et al. $(1983,1985)$ y la presencia de clastos estriados confirma su origen glacial (tillita).

\section{FACIES DE ARENISCAS MAL SELECCIONADAS GRADADAS (FACIES 12)}

Estos depósitos se reconocieron únicamente en el flanco occidental del anticlinal de Zapla (Fig. 1) en el tope de formación homónima.

Son capas de areniscas cuarzosas amarillentas con desarrollo de gradación normal y términos laminados hacia el tope y espesores variables entre $0,1 \mathrm{y}$ $0,5 \mathrm{~m}$. En su base poseen buen desarrollo de turboglifos. Ocasionalmente, se encuentran amalgamadas y de acuerdo con su continuidad lateral pueden clasificarse como lenticulares a intermedias dado que se acuñan lateralmente en el orden de la centena de metros.

Internamente, desarrollan una sutil gradación inversa próxima a la base y gradación normal en el resto de la capa. En la parte superior de algunas capas se desarrolla laminación paralela difusa y laminación cruzada. Dentro de este término resaltan algunos gránulos sobredimensionados (hasta de $1 \mathrm{~cm}$ ) que tienen aspecto de clastos caídos. Desde el punto de vista textural, las areniscas son marcadamente bimodales y la fracción gruesa (sabulítica) posee una muy buena redondez. La rocapresenta una marcadacementación. Interpretación. Se la interpreta como depósitos inducidos por flujos gravitacionales turbulentos en los que se verifican varias de las texturas y estructuras típicas; entreellas, gradación inversa-normal, laminación difusa y cruzada de pequeña escala. La escasez de matriz y el soporte dominantemente granular como así también la presencia de marcas erosivas (turboglifos), indican mecanismos de transporte a partir de flujos turbidíticos de alta concentración con desarrollo de turbulencia. La mezclagranulométricay labimodalidad es común en flujos turbulentos. Asimismo, la presencia de clastos sobredimensionados podría explicarse a partir de fuerte turbulencia o como efecto de la caída de clastos desde cuerpos de hielo flotante (balsaje). 
Esta facies es comparable con la facies Dmg de Eyles et al. (1983, 1985).

Lageometría lenticular de estas facies y la frecuente amalgamación de cuerpos permite interpretarlas como depósitos canalizados. En este sentido, se observan terminaciones ascendentes de tipo solapamiento expansivo ('onlap') contra superficies basales erosivas.

\section{FACIES DE ARENISCAS MAL SELECCIONADAS FINAMENTE ESTRATIFICADAS (FACIES 13)}

Esta facies se desarrolla comúnmente hacia el tramo superior de la Formación Zapla y se dispone en contacto neto sobre las diamictitas macizas.

Son sucesiones relativamente delgadas de fangolitas guijarrosas con estratificación muy delgada $(1-2 \mathrm{~cm})$ donde se intercalan láminas muy finas $(\sim 0,1 \mathrm{~cm})$ de material pelítico. Las capas de fangolitas guijarrosas son fangosoportadas e incluyen clastos subangulosos de tamaños variados que, en general, no superan los $2 \mathrm{~cm}$. No obstante, hay casos en los que el tamaño máximo de clasto duplica el espesor de capa.

Interpretación. Estas diamictitas bandeadas son comparables con las diamictitas estratificadas (Dms) de la clasificación de Eyles et al. $(1983,1985)$. Se interpretan como una alternancia de lluvias masivas de clastos ('rain-out till') separadas por intervalos de decantación pelítica a partir de suspensión a través de una columna de agua. El hecho de que ocasionalmente el tamaño máximo de clasto supera el espesor de las capas indica la frecuente superposición de procesos de caída individual a partir de balsaje glacial.

\section{FACIES PELÍTICAS CON CLASTOS CAÍDOS (FACIES 14)}

Se desarrolla en contacto transicional sobre la facies 13 y está particularmente bien representada en la Formación Zapla, en ambos flancos del anticlinal.

Se trata de pelitas arcillosas verdes oscuras a negras, finamente laminadas, que ocasionalmente contienen clastos sobredimensionados, de hasta 10 cm de diámetro, que incurvan la laminación. La composición de los clastos es normalmente de areniscas, pero se han hallado de limolitas y de rocas graníticas. Si bien las formas son subredondeadas algunos clastos presentan caras aplanadas y estrías subparalelas al eje mayor.

Esta facies alcanza un espesor de 1,75 m. En el flanco oriental se intercalan algunas delgadas láminas arenosas con trenes de ondulitas hambrientas ('starved ripples'). Intervalos muy delgados de pelitas negras se intercalan entre las areniscas mal seleccionadas y gradadas (facies 12). Interpretación. Se trata de depósitos de arcilitas laminadas producto de decantación subácuea. La presencia de clastos dispersos perturbando la delicada laminación y produciendo una notable inflexión (particularmente mejor desarrollada en la base) permite interpretar estructuras de percusión que son propias de clastos caídos. Este tipo de estructura es muy común en ambientes periglaciales si bien puede estar presente en otros contextos. La presencia de estrías y superficies planas en los clastos constituye, en cambio, una evidencia unívoca de la actividad modeladora de hielo. Se corresponde con la facies Fd ('fines with dropstones') de Eyles et al. (1983 y 1985). Los niveles con delgadas óndulas de arenisca fina se habrían acumulado por efectos de flujos diluidos del tipo delasturbiditas debaja concentración, que suelenformar trenes de óndulas saltuarias, de escaso relieve.

\section{FACIES DE ARENISCAS FERRUGINOSAS (FACIES 15)}

Fue reconocida en el curso superiory en la margen derecha del curso inferior del río Capillas, cubriendo a la Formación Zapla.

Se trata de cuerpos de colores pardo-violáceos, medianos a gruesos (con espesores máximos de 2,20 m), con geometría tabular, localmente adelgazados y compuestos por abundantes ooides ferruginosos. Estos depósitos presentan evidencias de bioturbación reflejada por un intenso moteado. En su interior están formados por varias capas macizas de entre 15 y $1,5 \mathrm{~cm}$ de espesor, con geometrías irregulares y en parte nodulares, que lateralmente se reemplazane interdigitan entre sí. Hacialabase comprenden intraclastos pelíticos y algunos nódulos fosfáticos subredondeados y gránulos de cuarzo. En afloramientos en sectores de la mina Puesto Viejo (Fig. 1), esta facies presenta un desarrollo de estratificación cruzada sigmoidal de hasta 2,1 m de espesor y terminaciones tangenciales tanto por la base como por el techo.

Al microscopio dentro de estos horizontes ferríferos es posible reconocer sectores con mayor enriquecimiento de componentes clásticos (cuarzo y micas), presentando el conjunto una fuerte cementación hematítica que le imprime la coloración rojiza. Las partículas ferruginosas son fundamentalmente granos recubiertos ('coated grains'), bien redondeados 
(entre 0,2 y $0,5 \mathrm{~mm}$ ), compuestos por chamosita dispuesta en láminas concéntricas o cortezas con grados variables de oxidación. Estas oolitas pueden tener secciones más prismáticas cuando se encuentran fuertemente compactadas o en la proximidad de superficies de disolución que separan capas. No se hallaron bioclastos.

Interpretación. Aunque los depósitos, en general, carecen de estructuras mecánicas visibles, por su textura, buena selección, escasa matriz fangosa y disposición tabular pueden interpretarse como depósitos de alta energía. Los bancos con estratificación cruzada, identificados másal sur, indicarían lapresencia de barras con influencia de mareas. En este sentido, los sigmoides con terminación tangencial y cubiertas de fango resultan estructuras diagnósticas de procesos mareales. Los colores rojizos que posee el depósito se deben a procesos de oxidación que corresponden a una marcada alteración diagenética y superficial. De lo contrario, este tipo de depósitos de hierro chamosítico suele presentar colores verdes.

Con respecto a la génesis, puede ser tanto primaria, vinculada a variaciones de las concentraciones de hierro disuelto (Bossi y Viramonte, 1975; Bradshaw et al., 1980; Frakes y Bolton, 1984; Van Houten, 1986; Cotter, 1988) y potenciadas por oscilaciones del nivel del mar y desarrollo de microambientes de precipitación (e.g., estuarios), como secundaria, a partir de reemplazo diagenético temprano de ooides carbonáticos (Kimberley, 1979 y 1980).

\section{FACIES DE ARENISCAS MICÁCEAS FANGOSAS (FACIES 16)}

Esta facies aparece en la Formación Lipeón.

Se trata de areniscas limosas verde-amarillentasa grises oscuras, con abundante mica y afectadas por intensa bioturbación. La estratificación es mediana a delgada, aunque de pobre resolución. Labioturbación ha borrado en parte la estructuración primaria y fundamentalmente se reconocen Chondritesy Zoophycos como formas dominantes. Las segundas están bien representadas en los planos de partición y llegan atener diámetros de lóbulo de hasta $35 \mathrm{~cm}$. Chondrites corta a Zoophycos estando representada por tubos de pequeño diámetro $(\sim 0,2-0,3 \mathrm{~cm})$ y relleno más fino.

Interpretación. Dado que no pueden reconocerse estructuras sedimentarias mecánicas resulta difícil establecer una interpretación hidrodinámica de esta facies. La intensa bioturbación y mezcla que le otorga el aspecto fangoso a la unidad indicaría que se trata de facies de plataforma asignables a la icnofacies de Zoophycos dominada por faunas detritívoras de baja icnodiversidad. Para Frey y Seilacher (1980) y Frey y Pemberton $(1984,1985)$ la oxigenación pobre es un factor clave en la presencia de esta asociación.

\section{ASOCIACIONES DE FACIES}

\section{ASOCIACIÓN DE LLANURAS DE MAREA}

Agrupa a las facies 1 y 2 que corresponden a depósitos de llanura de marea mixta, desarrolladas en un sector intermareal, con dominio de corrientes de flujo y reflujo. Las transiciones hacia llanura arenosa o hacia la llanura fangosa están representadas, respectivamente, por el dominio de estratofábricas lenticular a flaser y lenticular a ondulosa. La llanura mixta se desarrolla entre el límite de la marea alta (pleamar) y el límite de la marea baja (bajamar), donde la transición a la llanura fangosa refleja niveles de menor energía dominada por procesos de decantación.

También se incluyen en esta asociación las facies $6 a$ y b, las cuales son producto de la migración de formas de lecho del tipo de las dunas y se interpretan como relleno de canales mareales que surcanlallanura, siendo estrechos y sinuosos en el sector intermareal alto. Estas facies hacia su parte superior muestran claras evidencias de somerización y exposición subaérea, como lo indica la facies 5 con importante desarrollo de pavimentos poligonizados. Por otro lado, la intercalación con la facies 4 puede deberseal desarrollo de flujos densos dentro de estos canales fluviales, mientras que la facies 3 aparece ligada con superficies erosivas que podrían interpretarse como depósitos residuales producto de erosión y acumulación de depósitos fosfáticos previos.

\section{ASOCIACIÓN DE PLANICIES ARENOSAS SUBMAREALES}

Esta incluye las facies 6a, by c, que representan depósitos de barras activas e inactivas y áreas de interbarra, con claro domino de mareas, donde es posible reconocer una jerarquía completa de formas 
de lecho típicas de acción mareal. Las dunas de arena permiten inferir una posición submareal de estos depósitos, posiblemente en correspondencia con la porción axial de sistemas estuarinos macromareales, donde los complejos de barras poseen una elongación paralela a las corrientes de flujo y reflujo.

La transición de la planicie mixta a la planicie arenosa, en situación submareal está representada por la facies 5 . En este sector, la bioturbación es tan intensa que borra todas las estructuras primarias, conservándose algunos vestigios de ritmicidad arena-pelita (marealitas). Localmente, se observan transiciones entre la facies 5 y la 2 tratándose de intervalos con mayor relación inicial de arena-pelita.

\section{ASOCIACIÓN FLUVIO-ESTUARINA}

La facies 8 (areniscas sabulíticas macizas) se desarrolla en contacto neto ondulado y con carácter erosivo sobre asociaciones de planicie mareal. La granulometría y ausencia de evidencias paleontológicas e icnológicas indicativas de una génesis marina permite interpretar que estos depósitos pueden ser de origen fluvial, tratándose de facies residuales de fondo de canal. Además, esto es consistente con la naturaleza erosiva de sus contactos basales, evidenciando unfuertecontraste paleoambiental con la asociación de facies de planicies mareales.

\section{ASOCIACIÓN DE PLATAFORMA TRANSGRESIVA}

Las facies 9 y 10 representan depósitos de una plataforma situada, en general, por debajo de la acción del oleaje de buen tiempo, con superposición de eventos detormenta. Éstapresentarelacionesarenisca:pelita que varían entre 1:10-1:5 en la base hasta 1:1 próximo al tope, describiendo un arreglo estratocreciente. Cabe remarcar que esta asociación es la única que presenta faunas de un ambiente marino franco.

\section{ASOCIACIÓN DELTAICA}

Esta asociación está representada por las facies 1, 2, 4, 7y 9. Si bien la característica saliente es el arreglo estratocreciente representado por el pasaje entre las formaciones Capillas y Centinela, no se individualiza nítidamente la división tripartita que caracteriza a deltas fluviodominados. Esta es una característica propia de los deltas dominados pormareas (deltas destructivos) donde la acción combinada de mareas y oleaje con- tribuyen a la rápida dispersión de los sedimentos (Bhattacharya y Walker, 1992).

El arreglo estratocreciente entre las formaciones Capillas y Centinela está acompañado por la progresiva desaparición de faunas marinas abiertas y el incremento gradual de la bioturbación. Ello implica la progradación de un sistema deltaico, donde la estratofábrica resulta del proceso modelador dominante. Así, por ejemplo, la facies 7 denota condiciones de alta energía, similares a las que caracterizan a una cara de playa ('shoreface') superior a medio. En tal sentido, Buatois et al. (2002) señalaron que la cara de playa media es el ambiente más propicio para el dominio de la icnofacies de Skolithos. No obstante en sectores más expuestos del frente deltaico se habría desarrollado la facies 4 , mientras que en los sectores más protegidos, con dominio de mareas, lo habrían hecho preferencialmente las facies 1 y 2 .

Es importante remarcar que si bien en depósitos de frente deltaico de sistemas fluviodominados, comúnmente se produce la inhibición de suspensívoros debido a la abundancia de partículas finas en suspensión, no ocurre lo mismo con sistemas dominados por oleaje o por mareas, en dónde es posible encontrar la icnofacies de Skolithos bien desarrollada (Gingras et al., 1998). Buatois et al. (2003) señalan la presencia de abundantes tubos verticales de suspensívoros en depósitos arenosos también interpretados como de frente deltaico en unidades ordovícicas de la Cordillera Oriental (Provincia de Salta, Argentina).

\section{ASOCIACIÓN DE PLATAFORMA GLACIMARINA}

Esta asociación agrupa al conjunto de facies de vinculación glacial y gravitacional. La facies 11 se interpreta como el producto de depósitos en masa procedentes, alternativamente, de la fusión masiva de labase de hielos flotantes o por flujos gravitacionales (tills de flujo o tills resedimentados). Éstos caracterizan a asociaciones subglaciales o proglaciales proximales donde se produce la acumulación inestable de diamictos durante etapas estacionarias o de retroceso (Boulton, 1975). Es común que estos depósitos estén sujetos a reflujo o removilización (tills de flujo; Hicock, 1990) los cuales son muy difíciles de reconocer (Dreimanis, 1979; Deynoux, 1985). En la zona de estudio, se han identificado niveles con lentes de areniscas que indican una marcada inestabilidad del sistema depositacional. Similares estructuras y patrones de depósito caracterizan a esta unidad a nivel 
regional, pudiendo tratarse de cuerpos arenosos depositados rápidamente, que con posterioridad, y cuando estaban aún inconsolidados, se deformaron por carga y licuefacción. En este sentido, la facies 12 representaría los niveles arenosos no deformados que, en conjunto, permiten sugerir rellenos de canales submarinos en ambientes de talud. Salvo las pelitas negras que se asocian no existen indicadores independientes de la paleobatimetría, pero se infieren situaciones relativamente profundas o fuera del alcance de la energía del oleaje.

Las facies 13 y 14 corresponderían a depósitos subácueos proglaciales del tipo de los tills de lluvia ('rain out tills') producidos a través de una columna de agua. La presencia de clastos caídos con estructuras de impacto bien desarrolladas indican procesos de balsaje glacial comunes en secuencias proglaciales. Asimismo, la presencia de niveles muy delgados de areniscas laminadas es concordante con la actividad de corrientes de fondo relativamente diluidas. Los restos palinológicos hallados (Rubinstein, 2003a y b) permiten sugerir un origen marino.

\section{ASOCIACIÓN DE BARRAS OOLÍTICAS ESTUARINAS}

Esta asociación está constituida por la facies 15 formada por acumulaciones en bancos oolíticos ferruginosos submareales, en un medio litoral somero con dominio de mareas (Brookfield, 1973; Talbot, 1974; Bayer et al., 1985). Varios autores sugieren asociaciones similares producto de eventos regresivos o de somerización (Hallam y Bradshaw, 1979; Bradshaw et al., 1980; Frakes y Bolton, 1984; Astini, 1992; Burkhalter, 1995; Collin et al., 2005). Estos autores mencionan este tipo de depósitos ligados con ambientes litorales, especialmente en aquellos restringidos por barreras 0 en cuencas interiores, donde fluctuaciones del nivel del mar producen condiciones cíclicas en el Eh, el pH y la concentración de materia orgánica. En este marco, los momentos de escasa oxigenación (transgresiones) pueden conducir a notables incrementos de la concentración de hierro en estado disuelto $\left(\mathrm{Fe}^{+2}\right)$, mientras que los de oxigenación (regresiones) conducen a su precipitación (Curtis y Spears, 1968). Estos procesos se maximizarían en ambientes de albuferas y estuarios costeros donde los efectos de las mareas suelen también potenciarse, explicando así su acumulación y la consiguiente formación de barras.

\section{ASOCIACIÓN DE PLATAFORMA FANGOSA}

Esta asociación está constituida por la facies 16, de areniscas micáceas fangosas, y aparece sobre la asociación anterior. En su base se desarrolla un delgado intervalo conglomerádico con abundantes clastos redondeados de cuarzo. Esta asociación representaría ambientes de plataformas marinas, situados por debajo de la acción del oleaje, donde la fauna de fondo habría contribuido a generar la intensa bioturbación (icnofacies de Zoophycos).

\section{CONTENIDO ICNOLÓGICO}

La abundancia de trazas fósiles en el perfil del río Capillas permite su utilización como herramienta de análisis paleoambiental independiente. Se sabe que la zonación batimétrica utilizada por décadas y originalmente propuesta por Seilacher (1964 y modificaciones subsecuentes), presenta anomalías dependientes de un conjunto de factores físicos (e.g., tipo de sustrato, energía, contenido de nutrientes, oxigenación, salinidad y tasas de sedimentación y erosión) sólo indirectamente vinculados con la batimetría (Buatois et al. 2002).

En la sección del río Capillas se reconocieron 4 icnofacies, que se detallan a continuación:

\section{ICNOFACIES DE CRUZIANA}

En la Formación Zanjón y el Miembro Laja Morada de la Formación Labrado asociada a la facies 1, la icnofacies de Cruziana está representada por niveles con abundante Cruziana isp. y Rusophycus isp. Cruziana isp. se desarrolla en las bases o techos de capas de areniscas con estratificación delgada a muy delgada y contribuye, notablemente, a remarcar la lenticularidad del depósito (Fig. 4A). Rusophycus isp. aparece en los topes de algunas areniscas más gruesas (Fig. 4B) 

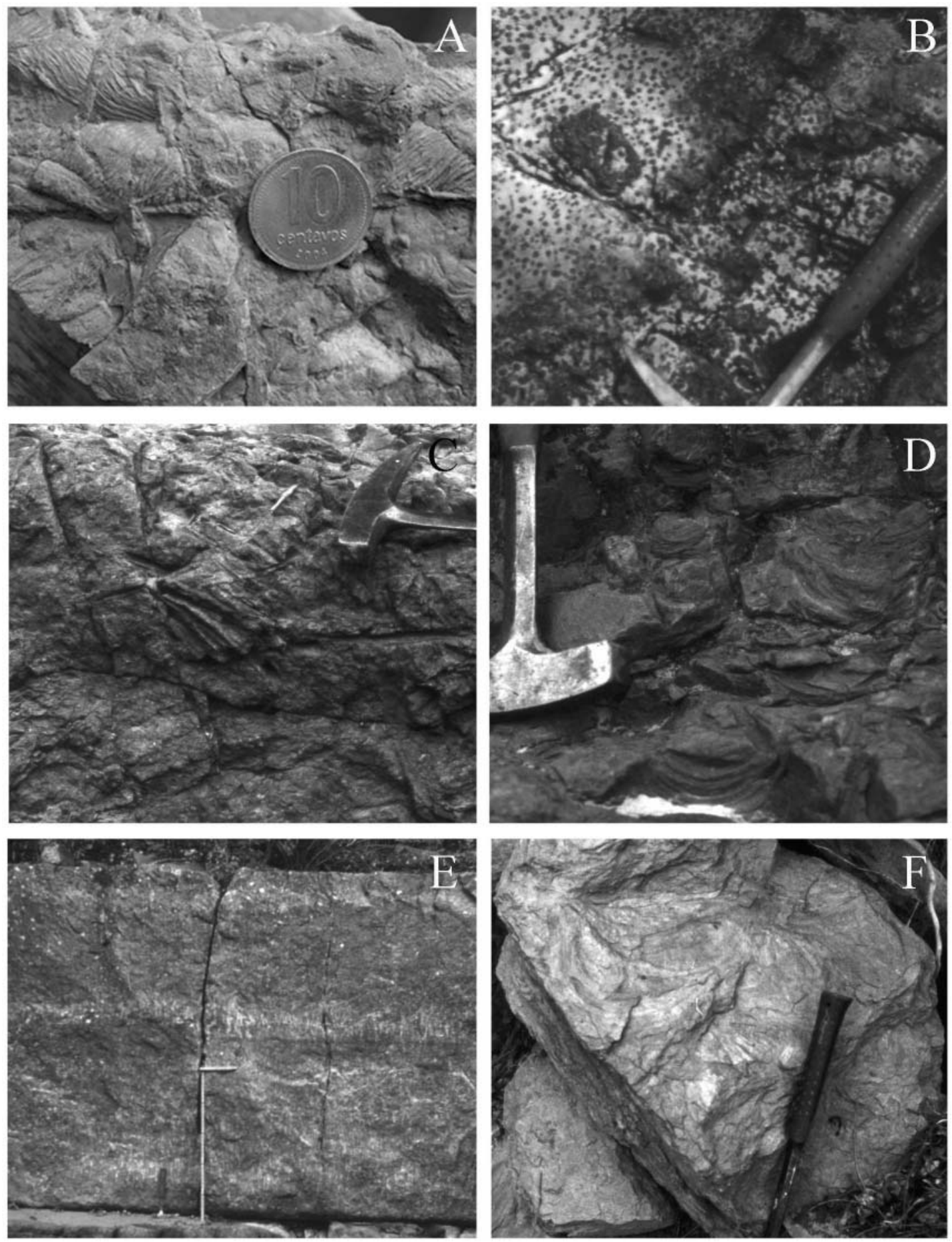

FIG. 4. A. Trazas de Cruziana isp. cortadas por grietas de desecación (Icnofacies de Cruziana). Miembro Laja Morada, Formación Labrado; B. Rusophycusisp. (preservación epicnia) cortados por tubos verticales tipo Skolithos (Icnofacies de Cruziana). Formación Zanjón; C. Phycodes isp. (Icnofacies de Cruziana) vistas en planta. Formación Capillas; D. Diplocraterion isp. (Icnofacies de Skolithos). Miembro Laja Morada, Formación Labrado; E. Trazas de tubos verticales tipo Skolithos (Icnofacies de Skolithos). Miembro Lagunillas, Formación Labrado; F. Zoophycos isp. Se aprecian los lóbulos en planta (Icnofacies de Zoophycos). Formación Lipeón. 
Con respecto a la secuencia temporal de emplazamiento, se pueden diferenciar por un lado, los ejemplares de Cruziana y Rusophycus asociados a la facies heterolítica delgada, que indican la existencia de organismos bentónicos que habitaron sustratos blandos con niveles de energía variable. Estas formas permiten interpretar que dichos organismos desarrollaron una variada gama de comportamientos entre los que se puede mencionar alimentación, reposo y pastoreo. Estas excavaciones son, en general, predepositacionales y se preservan como hipicnias (o preevento), aunque hay, en menor medida, variedades preservadas como surcos supraestratales (epicnias o posevento). Tubos de Skolithos cortan todo el resto de las trazas y estructuras mecánicas, correspondiendo a trazas tardías o posdepositacionales, y representando la última etapa de colonización por parte de organismos suspensívoros.

Desde un punto de vista icnofacial, en la facies 1 se superponen trazas comunes tanto en la icnofacies de Cruziana (con baja diversidad) como de Skolithos. Sin embargo, ambas asociaciones representan distintos momentos de colonización del sustrato inducidos por sucesivos cambios en las condiciones ambientales. Esta superposición es característica de la planicie mareal mixta donde la facies heterolítica es la más representativa.

En la Formación Capillas y relacionada con la facies de pelitas verdes la icnofacies de Cruziana se encuentra representada por Cruziana isp. y Phycodes isp. (Fig. 4C). La primera aparece muy poco representada, si bien en algunos sectores pueden diferenciarse trazas relícticas. Por el contrario Phycodes es la traza dominante y se presenta comúnmente en niveles tabulares, sensiblemente más arenosos, en donde borra todo tipo de estructuras. En este caso se trata de una forma dominante con desarrollo monoespecíico excluyente. La abundancia de esta traza indica importante actividad detritívora de las faunas de fondo y posiblemente elevadas tasas de material en suspensión que inhibieron el accionar de comunidades dominadas por organismos suspensívoros. Phycodes es una forma típica de la icnofacies de Cruziana (Buatois et al., 2002) e indica niveles energéticos bajos a moderados, por encima de la base del oleaje de tormenta hasta el nivel de base de olas normales, en una zona comprendida entre la cara de playa inferior ('shoreface') y el plataforma externa ('offshore') inferior (MacEachern y Pemberton, 1992a; MacEachern et al., 1999).

\section{ICNOFACIES DE SKOLITHOS}

Esta icnofacies es la más común a lo largo de toda la columna sedimentaria del río Capillas. Se encuentra representada por Skolithos isp., Diplocraterion isp. y tubos verticales indeterminados.

Como se aclaró anteriormente en la Formación Zanjón y Miembro Laja Morada de la Formación Labrado, es posible encontrar la icnofacies de Skolithos asociada con la icnofacies de Cruziana. Los tubos de Skolithosjunto a grietas de sinéresis suelen cortar las trazas de la icnofacies de Cruzianapertenecientes a una etapa de colonización previa (Fig. 3B).

Dentro de las mismas unidades formacionales, pero relacionadas con la facies de areniscas fangosas bioturbadas, se destaca la presencia de Diplocraterion (Fig. 4D) como traza dominante. En general, son formas de tipo retrusivo (en secciones se observa una disposición interna ascendente de los tubos causativos). En planta, estas excavaciones se diferencian de Skolithos por el apareamiento clásico de sus dos marcas circulares dejadas por los tubos verticales en 'U' y un surco de diámetro constante con geometría cóncava que los une. La bioturbación tiene aspecto de ser monoespecífica, ya que los niveles densamente poblados de Diplocraterion, no permiten ver otras trazas o estructuras previas (Fig. 4D). EI hecho de que no se pudieron observar los tubos causativos indica fluctuaciones importantes de la relación entre sedimentación-erosión, que favorecieron el desarrollo de estas trazas. En este sentido, podrían estar indicando un delicado equilibrio entre estos factores y considerarse como una 'trazas de equilibrio' o Equilibrichnia (Bromley, 1990). Esta traza sugiere un sustrato blando, posiblemente de menor competencia que los niveles con Skolithos, que alberga organismos suspensívoros.

En el Miembro Lagunilla de la Formación Labrado y asociada a la subfacies de areniscas con estratificación cruzada de microescala, Skolithos es también la traza dominante (Fig. 4E). Aparece cortando grietas de sinéresis y trenes de ondulitas de interferencia. Con menor frecuencia pueden observarse epicnias de Cruziana muy extensas. Los tubos de Skolithos sobreimpuestos reflejan el asentamiento de comunidades suspensívoras previas a la exposición subaérea.

En la Formación Centinela, tubos verticales, semiverticales y en forma de ' $Y$ ' de hasta $15 \mathrm{~cm}$ de largo pueden ser reunidos dentro de la icnofacies de 
Skolithos. Se trata de tubos verticales de sección circular y diámetro constante con valores entre 0,3 y $0,6 \mathrm{~cm}$ y con largos de hasta $30 \mathrm{~cm}$, que raramente exhiben meniscos. Por su densidad, es común que obliteren las estructuras internas que no quedan preservadas y su gran abundancia permite la formación de estructuras en empalizada (Droser, 1991), nombre que se da a unidades con el máximo índice de icnofábrica caracterizadas por tubos verticales.

\section{ICNOFACIES DE GLOSSIFUNGITES}

Hacia el tope de la Formación Labrado se desarrollan alternancias de areniscas limosas y pelitas en capas medianas a delgadas. Esta asociación está interrumpida por una superficie neta y ondulada, particularmente bioturbada por tubos verticales de hasta $10 \mathrm{~cm}$ de profundidad y diámetro promedio $>$ a $1 \mathrm{~cm}$ (y hasta de $2 \mathrm{~cm}$ máximo). Estos tubos están rellenos con una arenisca limpia, muy gruesa y mal seleccionada, que contiene granos subredondeados de hasta 2 $\mathrm{mm}$ de diámetro. El contraste litológico entre el relleno de los tubos y el sustrato hospedante permite interpretar que el material grueso se habría infiltrado desde el tope hacia abajo en cavidades que permanecieron al menos parcialmente abiertas durante episodios de mayor energía. Dado que la unidad suprayacente tampoco posee estas litologías gruesas se interpreta esta superficie como una superficie de pasaje (discontinuidad de 'by-pass'), que denota el desarrollo de un sustrato firme (MacEachern et al., 1999). Esta asociación de tubos verticales es asignada a la icnofacies de Glossifungites (Pemberton et al., 1992a; MacEachern y Pemberton 1992a; Pemberton y MacEachern, 1995), que resulta importante en el reconocimiento de discontinuidades erosivas (Pemberton et al. 1992a y b; MacEachern y Pemberton, 1992a y b).

\section{ICNOFACIES DE ZOOPHYCOS}

En la Formación Lipeón, en donde dominan las facies deareniscas micáceas, se desarrollalaicnofacies de Zoophycos, reconociéndose tanto Chondrites como Zoophycos (Fig. 4F). La intensa bioturbación, que, en general, borra las estratofábrica y estructuras primarias le otorga un aspecto fangoso a la unidad, indicando que se trataría de facies de plataforma dominada por faunas detritívoras de baja icnodiversidad. Para Frey y Seilacher (1980) y Frey y Pemberton $(1984,1985)$ la oxigenación pobre del sustrato es un factor clave en la presencia de esta asociación, mientras que el factor batimétrico toma un papel secundario.

\section{EVOLUCIÓN DEL RELLENO SEDIMENTARIO Y ESTRATIGRAFÍA SECUENCIAL}

El estudio de la sucesión ordovícica expuesta en ambos flancos del anticlinal de Zapla permite el reconocimiento de cuatro secuencias depositacionales (S1-S4 de Astini et al., 2003) con diferente arreglo interno y que, de acuerdo con el intervalo de tiempo involucrado, resultan compatibles con fluctuaciones de tercer orden (Fig. 5). Para el conjunto de los depósitos que caracterizan al intervalo ordovícico en la Cuenca Andina Central del noroeste argentino, Astini (2003) reconoció ocho supersecuencias, varias de las cuales son claramente reconocibles en la estratigrafía de las sierras Subandinas (Fig. 5).

La columna del río Capillas comienza con depósitos de la asociación 1 correspondiente a llanuras de marea, donde tanto los sectores intermareales (llanura fangosa, mixta y arenosa) como los submareales (planicies arenosas), aparecen bien representados. Los niveles con pavimentos agrietados constituyen clara evidencia de lapsos de exposición subaérea en sectores supramareales (tramo superior de la Formación Zanjón y transición al Miembro Laja Morada de la Formación Labrado). Intervalos con capas de areniscas discretas pueden, en este contexto, representar episodios de tormentas que removilizan y concentran material arenoso en forma diferencial y acumulan bioclastos (concentraciones de braquiópodos linguliformes y microconglomerados fosfáticos). Esta asociación basal puede representar sectores de centro de estuario donde dominan litologías finas ocasionalmente intercaladas con cuñas de arena o bancos de mayor potencia que pueden reflejar la actividad de canales vinculados a deltas de cabecera de estuarios (Rahmani, 1988; Dalrymple et al., 1992).

El reemplazo vertical de icnofacies en este tipo de ambientes dominados por procesos mareales es opuesto al de una costa dominada por oleaje 


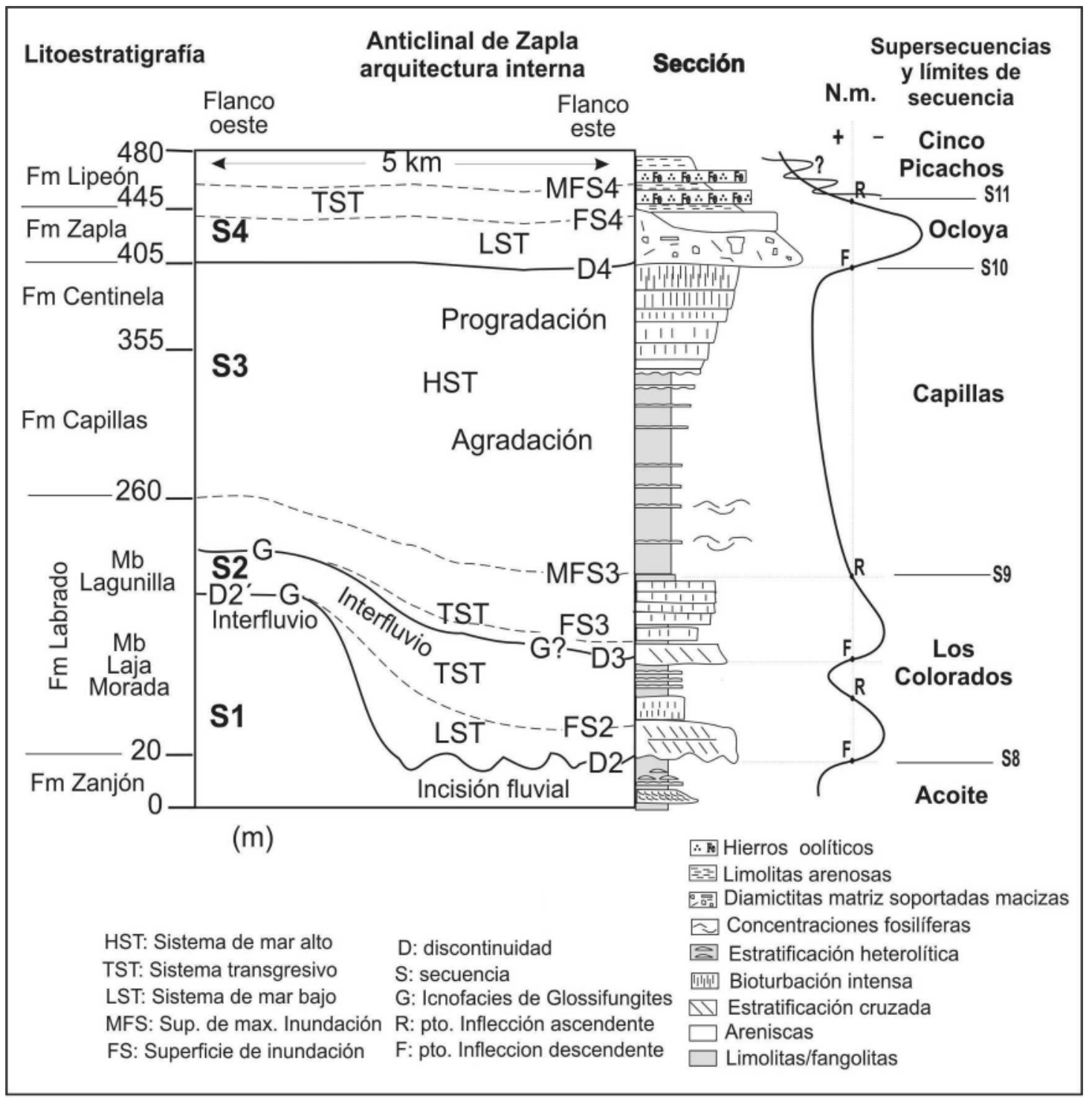

FIG. 5. Columna sintética del Ordovícico de la sierra de Zapla y curva relativa del nivel del mar interpretada para la región (véase explicación en el texto) (modificada de Astini y Marengo, 2003).

(Mangano y Buatois, 1999, 2003). Los complejos de ondas de arena submareales arenosos que representan los sustratos con mayor nivel de energía, contienen hacia el tope asociaciones de organismos suspensívoros monoespecíficos asignables a la icnofacies de Skolithos. Por encima, se disponen depósitos de areniscas delgadas de planicie arenosa (intermareal baja) y facies heterolíticas de la planicie mixta (intermareal media), que presentan una mezcla de elementos de la icnofacies de Skolithos y Cruziana. Las formas de la icnofacies de Cruziana se hacen más importantes hacia la planicie intermareal alta, donde la menor energía permite la decantación de sedimentos pelíticos, dominados por formas detritívoras. Es importante resaltar que la baja icnodiversidad que caracteriza a estas icnofacies se asocia a condiciones de estrés posiblemente resultantes de la dilución del agua marina, de acuerdo con el 'modelo de aguas salobres' propuesto por Wightman et al. (1987) y Pemberton y Wightman (1992) para el reconocimiento de valles estuarinos. 
Los ciclos arenosos de la Formación Labrado (parte superior del Miembro Laja Morada y Miembro Lagunilla) representan la instalación de típicos sistemas fluviales, que se reconocen a través de dos ciclos granodecrecientes, desarrollados sobre depósitos de planicies submareales con base erosiva (Figs. 6A, B y C). La incisión del primer ciclo (Figs. 6 A y B) es localmente mucho más evidente a través de estructuras de corte y relleno de escala métrica que afectan a un sustrato fuertemente oxidado y con pavimentos de grietas de desecación (Fig. 6D). Se trata del principal límite de secuencia (D2-D2') que posee pronunciadas variaciones laterales a lo largo del eje del paleovalle fluvial (Figs. 6D y E). D2-D2' puede correlacionarse con la superficie S8 de Astini (2003), que separa la Supersecuencia Acoite de la Supersecuencia Los Colorados (Fig. 5).

Debe destacarse que el límite de secuencia no queda marcado por la transición gradual entre la Formación Zanjón y el Miembro Laja Morada que, salvo un gradual cambio en la coloración, no muestra evidencias claras de mayor exposición subaérea. Por el contrario, a pesar de su coloración rojo-morada, siguen apareciendo pavimentos de linguliformes, icnofacies de Cruziana y un dominio de facies heterolíticas. La marcada coloración rojo-morada que caracteriza al Miembro Laja Morada, al igual que el desarrollo de bandas con intenso moteado, representan un prolongado lapso de emersión asociado a la más profunda y prolongada caída relativa del nivel del mar que habría sometido a parte de las sucesiones marinas y marinas marginales de la Formación Zanjón a ambientes subaéreos con actividad fluctuante de la capa freática en ambientes de interfluvio. Esta prolongada situación emergente permite explicar el marcado cambio de coloración y la permanencia de condiciones oxidantes por encima de la posición de la capa freática estacionaria, en contraposición con las bandas de decoloración, con abundantes moteados, características de regiones del sustrato con condiciones glósicas (localmente reductoras), más propias de posiciones por debajo de la capa freática fluctuante. A pesar de las marcadas evidencias paleoambientales de exposición subaérea temporal (como por ejemplo pavimentos de grietas de desecación y trenes de ondulitas truncadas), son estas evidencias diagenéticas tempranas del cambio de coloración las que permiten sostener una prolongada emersión en vinculación con una caída relativa del nivel del mar, ocurrida durante el Darriwiliano medio, consistente con el labrado de la superficie D2-D2' (Fig. 5).
En el flanco este, la discordancia D2 se corresponde con la base de los depósitos de areniscas sabulíticas con estratificación cruzada e importante participación de intraclastos, mientras que en el oeste se correlaciona con un delgado intervalo de areniscas sabulíticas que recubren un nivel afectado por la icnofacies de Glossifungites (D2', ver figura 6E). Esto implica un corrimiento lateral desde la región axial de un sistema fluvial a una región de interfluvio. La suprayacente secuencia S2 involucra un cortejo de nivel de mar bajo (LST), representado por el relleno fluvio estuarino en la región axial y un cortejo transgresivo (TST), caracterizado por paquetes heterolíticos profusamente bioturbados desarrollados en posición submareal. Este último se sobrepone al anterior y solapa directamente la discordancia D2' en la región de interfluvio (flanco oeste).

En la base del Miembro Lagunilla es posible diferenciar un segundo límite de secuencia denominado D3 (Figs. 6C, Fy G). En el flanco oeste D3 involucra la icnofacies de Glossifungites, indicando una discontinuidad de magnitud regional desarrollada sobre sustratos firmes, compatible con unárea de interfluvios. Esto explicaría el desarrollo de una superficie de tránsito ('by-pass surface'), producida durante una nueva caída relativa, que permite explicar el relleno grueso residual de los tubos de Skolithos que no habrían sido eliminados por completo, por encontrarse fuera de la región axial de máxima incisión del sistema estuarino. El apilamiento vertical y aparente desfasaje entre los ejes axiales inferidos de sistemas estuarinos superpuestos, permite interpretar que habría existido una cierta acomodación lateral de dichos sistemas, posiblemente ligada con compensación de espesores y nivelación estratigráfica luego de cadaincisión.

Otra característica notable que puede observarse del arreglo estratigráfico en el río Capillas, es el desarrollo de superficies coplanares (cf., Posamentier y Allen, 1999) fuera de la región de máxima insición representada por los cuerpos canalizados arenogravosos. En un buen ejemplo, Rossetti y Junior (2004) destacan que en sectores de valles estuarinos donde no hubo depositación durante el estadio de nivel de mar bajo o donde los depósitos fluviales fueron removidos durante la transgresión subsiguiente, los depósitos trangresivos se apoyan directamente sobre el límite de secuencia. En estos casos se desarrollan superficies coplanares, donde las superficies transgresivas ('flooding surfaces') coinciden con la discordancia de caída, es decir los límites de secuen- 

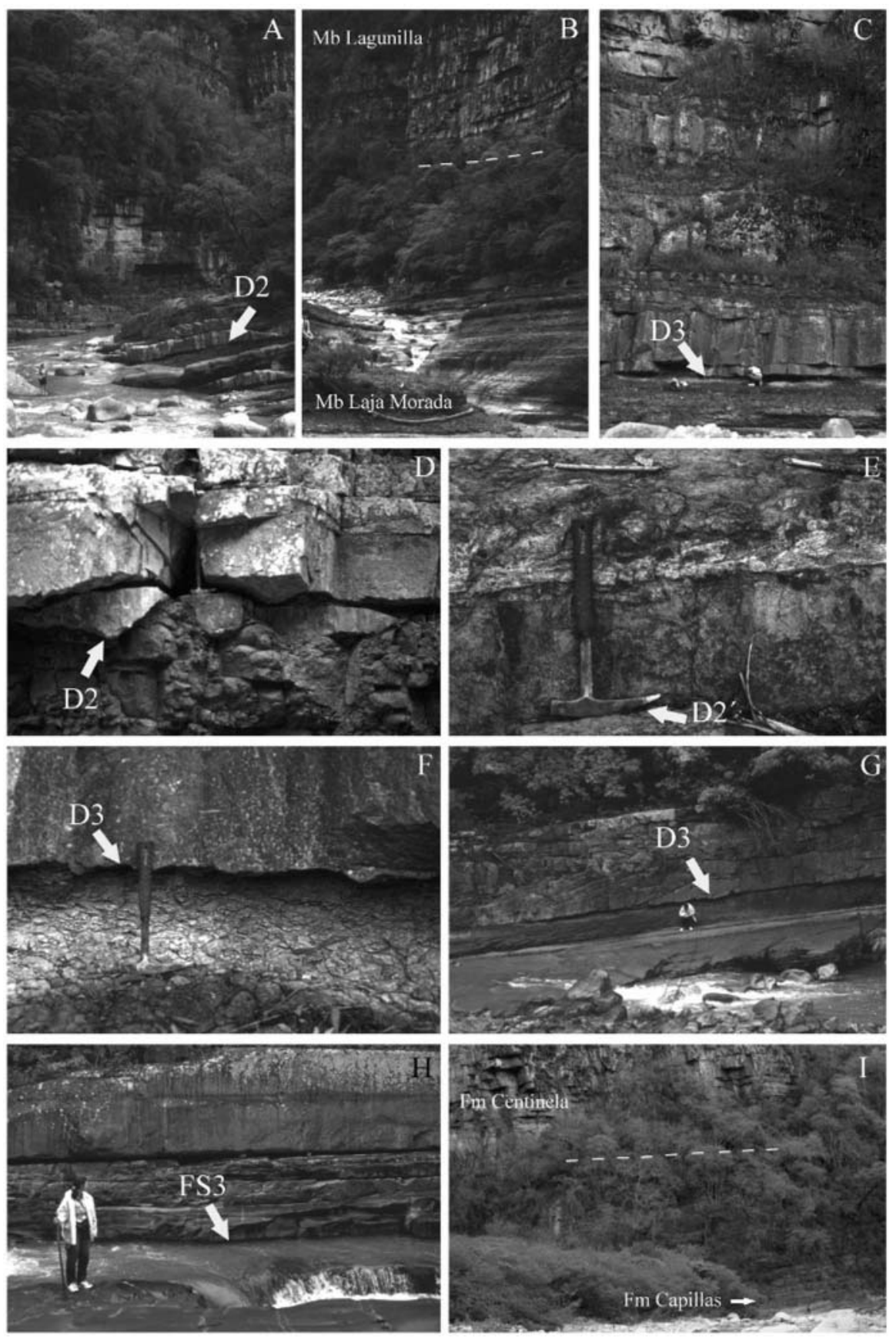

FIG. 6. A. Panorámica base del Miembro Lagunilla y $1^{1}{ }^{\circ}$ ciclo arenoso. Superficie D2. Formación Labrado; B. Panorámica Miembro Laja Morada (parte inferior) y el Miembro Lagunilla (parte superior). El contacto entre ambos está oculto por la vegetación, pero se aprecia en la parte superior el desarrollo del $1^{\circ}$ ciclo arenoso. Formación Labrado; C. Panorámica Miembro Lagunilla. Nótese contacto basal del $2^{\circ}$ ciclo arenoso. Superficie D3. Formación Labrado; D. Detalle de superficie D2 en la base del $1^{\circ}$ ciclo arenoso del Miembro Lagunilla. Nótese estructuras de corte y relleno. Flanco oriental del anticlinal de Zapla. Formación Labrado; E. Superficie D2' con asociación de la icnofacies de Glossifungites. Contacto Miembro Laja Morada- Miembro Lagunilla, Formación Labrado. Flanco occidental del anticlinal de Zapla; F. Detalle de C. Se observa la base del $2^{\circ}$ ciclo arenoso del Miembro Lagunilla. Superficie D3, flanco oriental del anticlinal de Zapla. Formación Labrado; G. Superficie D3. Contacto entre el Miembro Laja Morada y el Miembro Lagunilla de la Formación Labrado; H. Superficie de inundación FS3. Formación Labrado; I. Detalle de la transición entre la Formación Capillas y la Formación Centinela representada por el pasaje de la etapa agradacional a la progradacional. 
cia. En estos contactos (Fig. 5) ambas superficies se encuentran amalgamadas y de no identificar la arquitectura de valles incisos asociados, como en este caso, su reconocimiento y diferenciación en el registro fósil es muy difícil. Estos límites pueden confundirse con pequeños saltos de facies o sutiles variaciones ambientales, ya que no siempre queda preservada la icnofacies de Glossifungites o se verifican cambios granulométricos o cambios de color. En el flanco este del anticlinal, por ejemplo, la icnofacies de Glossifungites no aparece. Sin embargo, puede observarse claramente cómo una superficie de inundación (FS3) separa areniscas sabulíticas con estratificación cruzada difusa, de paquetes heterolíticos bioturbados (icnofacies de Skolithos) asignados a depósitos submareales (Fig. 6H). Esta es posiblemente la fisonomía que adquiere la superficie de ravinamiento o superficie transgresiva submareal cuando produce una cierta erosión durante el rápido corrimiento del cinturón de facies de alta energía sobre el de menor energía. Esto es consistente con la migración de complejos de ondas de arena submareales hacia el continente ('landward migration of sandy tidal inlets') (Zaitlin et al., 1994), que sobrepone esta asociación sobre la de la planicie fangosa costera.

Las características de los depósitos descritos sugieren un modelo de evolución general similar al propuesto por Dalrymple et al. (1992), en donde valles fluviales incisos durante etapas de caída relativa evolucionan a sistemas estuarinos durante la etapa transgresiva. En este sentido, los depósitos sabulíticos con geometría lenticular a la gran escala representan la acomodación de sistemas fluviales (luego de la etapa de incisión y pasaje) que evolucionan a un sistema con neta influencia mareal. Esto queda reflejado en el complejo de cuerpos de arena mantiformes con profuso desarrollo de estratificación cruzada sigmoidal y cubiertas pelíticas que caracterizan a su periodicidad y el fenómeno de reversión de mareas. Este último punto resulta evidente a partir del desarrollo de la planicie submareal arenosa. Alejándose del eje de los valles fluviales se interpreta la existencia de asociaciones de interfluvios caracterizadas por la ausencia de los depósitos arenosos de nivel bajo y el desarrollo de superficies con icnofacies de Glossifungites e intervalos de color rojizo.

La sucesión estratigráfica registra un cambio repentino a partir del desarrollo de la cuña pelítica que abruptamente cubre al miembro Lagunillas de la Formación Labrado. Se trata de la Formación Capillas que se interpreta en su sección basal como el produc- to de un rápido corrimiento del cinturón costero vinculado con la superficie de máxima inundación (MFS3). Desde un punto de vista estratigráfico secuencial, la sección basal de esta unidad representa una etapa de agradación temprana durante el desarrollo del cortejo de nivel de mar alto (HST), mientras que el paulatino enarenamiento se vincula con el inicio de la subsecuente etapa progradacional. El repentino incremento del espacio de acomodación luego de la inundación costera, habría generado condiciones propicias para el desarrollo de depósitos pelíticos con intercalaciones de capas de tormenta que indican su depositación en ambientes de plataforma marina abierta, por encima del nivel del oleaje de tormentas, afectadas por una icnofacies de Cruziana. Este corrimiento neto de la línea de costa, consistente con la superficie de máxima inundación, tiene, a nivel regional, correspondencia con la superficie S9 de Astini (2003) que limita la Supersecuencia Capillas (Fig. 5). En la Cordillera Oriental, este límite transgresivo se ubica en la base de la Formación Santa Gertrudis (en la región oriental) y en la base de la Formación Sepulturas (en la región occidental). Este notable intervalo marino caracterizado por la mayor diversidad de faunas de invertebrados marinos y la presencia de conodontes asociados con restos de Sacabambaspis janvieri (Albanesi y Astini, 2002) se registra también en Bolivia donde está representado por las formaciones Anzaldo y Coroico (Suárez Soruco, 1992; Astini et al., 2004). Dado que este intervalo marino se encuentra particularmente representado en esta región, es que Astini (2003) utilizó su nombre para nominar la Supersecuencia Capillas. La instalación de un ambiente de plataforma marina abierta contribuyó a inundar la planicie costera, eliminando los sistemas estuarinos que dominaron esta región hasta el Darriwiliano. En sentido ascendente, un gradual aumento del contenido de areniscas indica la progradación de la línea de costa y desarrollo de sistemas deltaicos que encuentran su máxima expresión en el desarrollo de los cuerpos de arena de la Formación Centinela, que representan una plataforma deltaica influenciada por mareas (Fig. 6l). Esto es compatible con los modelos estratigráficos (Posamentier et al., 1988; Posamentier y Vail, 1988) que predicen una paulatina disminución del espacio de acomodación durante los estadios finales de cortejos de nivel de mar alto (HST). La modificación morfológica de los sistemas costeros dominantes, por encima y por debajo de la superficie S9 (MFS 3 en el caso particular de la sierra de Zapla), es característica de la conversión evolutiva que sufren 
los sistemas de transición entre etapas de nivel de mar bajo y nivel de mar alto (Curray, 1964; Boyd et al., 1992; Dalrymple et al., 1992).

La Formación Zapla fue incluida dentro de la Supersecuencia Ocloya por Astini (2003) por la razón de que trunca diversas unidades ordovícicas en diferentes regiones del noroeste argentino. Este límite de secuencia puede reconocerse a lo largo de toda la Cuenca Andina Central, no sólo en el sector argentino sinotambién en el boliviano. Lasupresión estratigráfica indica claramente que existía un relieve que fue parcialmente nivelado por el episodio glacial del Ordovícico tardío que le dio origen. Si bien en muchas regiones coincide con la discordancia oclóyica, ésta constituye un episodio orogénico claramente diferente de la abrupta caída del nivel del mar que fue responsable de exponer regionalmente al sustrato preglacial. Por esta razón, si bien localmente pueden coincidir un efecto tectónico con uno glacioeustático en muchas regiones como la expuesta en las sierras Subandinas, la impronta tectónica no queda clara. Aparentemente, el episodio oclóyico sólo alcanzó la región más occidental del antepaís y en esta región relativamente externa los efectos sólo habrían causado exhumación. Si bien resulta difícil cuantificar el intervalo faltante por debajo de la Supersecuencia Ocloya, es justamente en la sierra de Zapla donde el hiato sería menor al alcanzar el tope de la Formación Centinela la parte superior de la Serie Global 5. Esto permite suponer que posiblemente el contacto representado por la discordancia D4 en esta región, tenga una componente fundamentalmente glacieustática a diferencia de otras regiones más internas en donde la componente tectónica habría magnificado la interrupción estratigráfica.
La asociación de facies de plataforma con dominio de procesos glacimarinos que caracterizan ala Formación Zapla en la sierra homónima se relaciona con un cortejo de nivel de mar bajo (LST de S4). Las evidencias bioestratigráficas disponibles indican que se trata del episodio glacial fini-ordovícico (Hirnantiano) que, con epicentro en el noroeste africano, tuvo influencia directa en gran parte de Gondwana y en particular a lo largo de la región proto-andina que, aunque periférica, habría nucleado calotas de altura (Astini, 2002, 2003). Las paleocorrientes sugieren que los depósitos canalizados habrían estado dirigidos hacia el este-noreste, indicando que el eje de la sedimentación hirnantiana ocurrió adyacente a una faja elevada y de posición occidental. De hecho la Supersecuencia Ocloya incluye depósitos continentales en la región de la Puna y parte occidental de la Cordillera Oriental (véase figura 1.40 en Astini, 2003).

Por último, la Formación Lipeón de edad silúrica (Montero, et al., 1993) inicia un cortejo transgresivo donde los mantos de hierro pueden localmente interpretarse como depósitos en engolfamientos o estuarios luego del inicio de la inundación (FS 4). Tras la superficie de máxima inundación (MFS 4) esta unidad constituye un dominio fangoso de plataforma que caracteriza regionalmente al intervalo silúrico, donde la icnofacies de Zoophycos reemplaza a la alternancia de Skolithos y Cruziana dominante durante el Ordovícico. Astini (2003) interpreta este pasaje como el límite de la Supersecuencia Cinco Picachos (véase Astini et al., 2004). En el marco de dicha transgresión, se habrían desarrollado situaciones costeras proclives para generar la precipitación de depósitos ferruginosos en ambientes relativamente oxigenados.

\section{ARQUITECTURA Y PALEOGEOGRAFÍA DE LA CUENCA}

Los cambios paleoambientales documentados en la columna del río Capillas (Fig. 5) proveen nuevos elementos de juicio para comprender la arquitectura del relleno sedimentario del sector oriental de la cuenca andina central, interpretada como la región externa del antepaís (Astini, 2003). El reconocimiento de discontinuidades regionales a lo largo de toda la sección permite realizar una correlación con áreas aledañas, principalmente de la Cordillera Oriental.

La aplicación de modelos de antepaís actualistas (DeCelles y Giles, 1996) en sedimentitas ordovícicas del noroeste argentino, permitió la integración de depocentros que previamente fueron considerados como desconectados (Fig. 7) (Astini et al., 2003). Modelos previos han sugerido la dispersión de sedimentos hacia la antefosa en gran parte proveniente del arco de la Puna occidental. Actualmente, hay suficientes evidencias que soportan la doble alimentación del sistema, con un importante aporte desde el este, relacionado con complejos deltaicos adosados al cratón (Astini y Waisfeld, 1993; Astini y Marengo, 2003). Estos deltas contribuyeron a incrementar la 


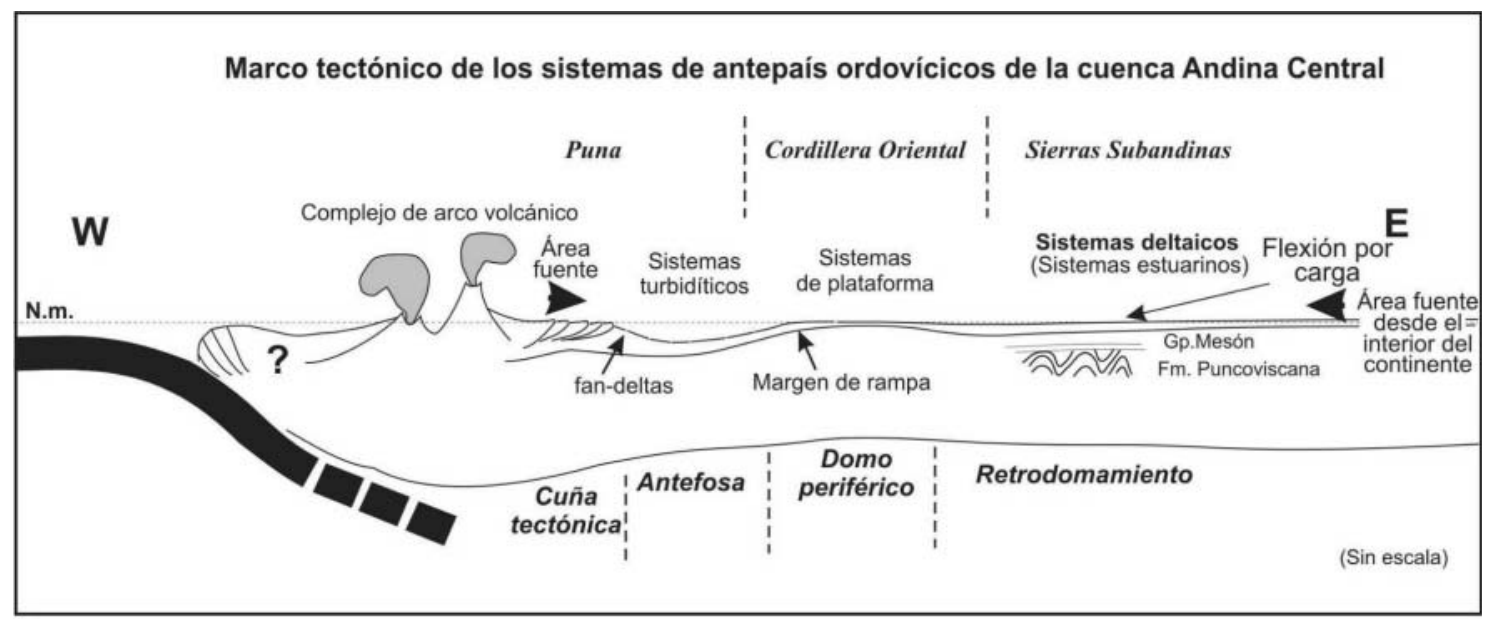

FIG. 7. Corte esquemático E-W del noroeste argentino mostrando la distribución transversal de espesores y el engranaje de depozonas en la cuenca de el antepaís ordovícica (modificado de Astini et al., 2003).

carga y la flexión dentro del depocentro de 'retrodomamiento' ('back-bulge depozone') (coincidente con las sierras Subandinas), independiente de los estadios de carga y descarga que acontecieron en el arco, al oeste (Bahlburg y Furlong, 1996). Asimismo, pueden haber sido controlados por variaciones climáticas ocurridas tierra adentro, comparable actualmente con el desarrollo del delta del Mississippi (Perlmutter y Matthews, 1992). Los ciclos de sobre carga-denudación han sido considerados como responsables de disparar la respuesta flexural (Bahlburg y Furlong, 1996) en la antefosa (coincidente con la región de la Puna) y en el domamiento periférico (coincidente con la Cordillera Oriental).

El hecho de que las sierras Subandinas ocupen una posición muy distal con respecto a la cuña tectónica, supone un depocentro poco afectado por la influencia tectónica. En este sentido, las fluctuaciones relativas del nivel del mar pueden ser consideradas como de posible origen eustático o global. Esto es consistente con el hecho de que los límites de secuencia como el D2 o el D4 tienen un registro regional amplio, desechando cualquier señal tectónica.

El arreglo general que presenta el depocentro de 'retrodomamiento' aquí estudiado y la naturaleza predominantemente marino marginal de las capas del Ordovícico en esta región, permiten interpretar la existencia de una carga deltaica extra, capaz de incrementar la flexión cortical en la región y la acomodación inusual de este tipo de depósitos en regiones del antepaís. La construcción de complejos deltaicos ha sido sugerida por Astini et al. (2003) como una explicación para generar cargas adicionales que habrían potenciado el espacio de acomodación, incluso en sistemas desarrollados sobre corteza continental (e.g., Watts, 2001: p. 150). Desde un punto de vista paleogeográfico, la región subandina habría sido un sitio de desarrollo de enormes aparatos deltaicos que drenaban la región de Gondwana occidental. Esta es la razón principal para explicar el gran espesor de las columnas sedimentarias ordovícicas de la Cuenca Andina Central, que se habrían formado en un corredor marino similar al desarrollado durante el Cretácico en el interior del oeste norteamericano (e.g., Swift et al., 1987). A diferencia de este último, sin embargo, nuestra interpretación regional y el sentido dominante de las paleocorrientes indica que la progradación deltaica rellenaba el espacio de acomodación de este a oeste (Fig. 8) ya que la principal fuente detrítica provenía desde la región cratónica. Esta hipótesis explicaría el gran espacio de acomodación requerido para la preservación de unidades en el ámbito subandino, no registradas en el ámbito de la Cordillera Oriental, como la Formación Centinela, que no tiene equivalentes hacia el oeste, pero está igualmente registrada en Bolivia, donde se correlaciona con la Formación San Benito (Suárez-Soruco y Benedetto, 1996), desarrollada en cinturones de facies de alta energía. 


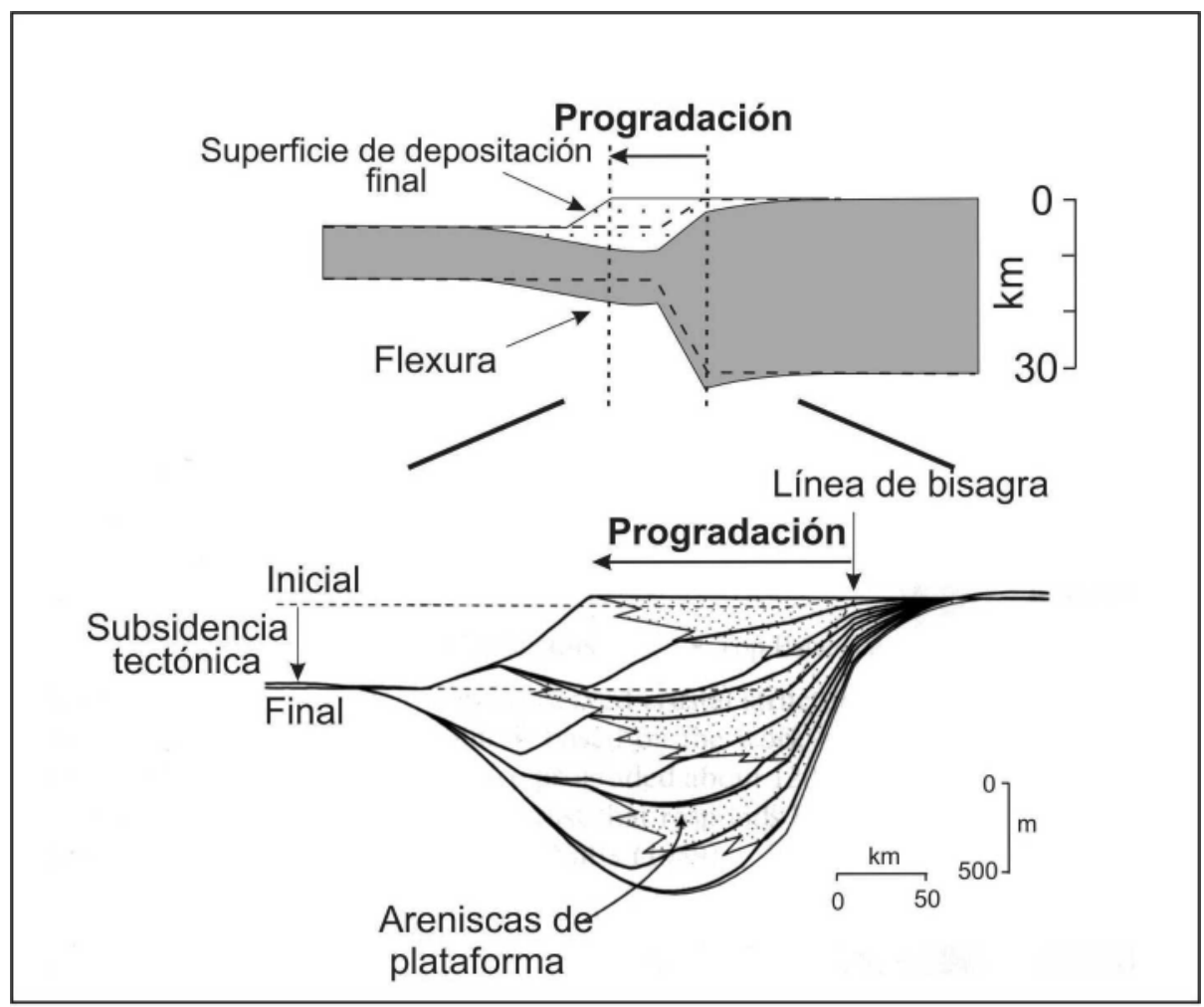

FIG. 8. Modelo simplificado de la estratigrafía y arquitectura de facies como consecuencia de la progradación de sistemas deltaicos en una cuenca subsidente (modificado de Watts, 1989, 2001). La carga induce flexión litosférica. Fluctuaciones en la acomodación se traducen en la repetición de secuencias depositacionales con similar arreglo de facies.

\section{CONCLUSIONES}

La columna medida sobre el curso inferior del río Capillas (anticlinal de la sierra de Zapla) representa un conjunto de sistemas depositacionales dominantemente marinos marginales alimentados desde el este.

Se definieron 16 facies reunidas en 8 asociaciones de facies y representando: 1. Asociación de llanura de mareas (Formación Zanjón y parte inferior de la Formación Labrado); 2. Asociación de facies de planicies arenosas submareales (Miembro Lagunilla, Formación Labrado); 3. Asociación fluvio-estuarina (Formación Labrado parte superior); 4. Asociación de facies de plataforma transgresiva (Formación Capillas); 5. Asociación deltaica (Formación Centinela), registra el pasaje a sistemas deltaicos; $\mathbf{6}$. Asociación de facies de plataforma glacimarina (Formación Zapla); 7. Asociación de facies de barras oolíticas estuarinas (parte inferior de la Formación Lipeón) y 8 . Asociación de plataforma fangosa (parte superior de la Formación
Lipeón). Las tres primeras asociaciones constituyen un dominio de ambientes estuarinos.

Considerando las principales características del arreglo estratigráfico y la utilización de superficies diagnósticas (discontinuidades) se reconocieron en este sector de las sierras Subandinas, cinco (Acoite, Los Colorados, Capillas, Ocloya y Cinco Picachos) de las ocho supersecuencias depositacionales, identificadas por Astini (2003) en el ámbito de la Cordillera Oriental.

Las Supersecuencias Acoite, Los Colorados y Capillas estarían representadas por sistemas deltaicos que desde el Ordovícico Inferior alto al Ordovícico Superior medio, evacuaron materiales desde la región cratónica de Gondwana (este) hacia el antepaís andino central (oeste). Las fluctuaciones relativamente rápidas del nivel del mar condicionaron la progradación de estos sistemas y los convirtieron durante intervalos 
significativos en sistemas estuarinos, labrando valles incisos durante las caídas y rellenándolos durante la historia transgresiva y de nivel alto. Durante estas últimas etapas, incluso rebasaron los límites geomorfológicos de los sistemas estuarinos para solapar interfluvios expuestos subaéreamente. Esto permitió el excepcional desarrollo de superficies coplanares (D2, D3) como las que se registran en el flanco oeste del anticlinal de Zapla, donde la incisión no habría sido marcada. En este marco, la Formación Capillas se destaca por constituir un intervalo de máxima inunda- ción y retracción de la línea de costa (sección basal agradacional del cortejo de nivel alto) antes de producirse una nueva progradación deltaica representada por la parte superior de esta unidad y el grueso de la Formación Centinela.

La Supersecuencia Ocloya representa el truncamiento de los depósitos anteriores a partir de la actividad glacial hirnantiana (finiordovícica), mientras que la Supersecuencia Cinco Picachos registra la inundación de todo el sistema debido a la transgresión posglacial, a partir del Silúrico.

\section{AGRADECIMIENTOS}

Deseamos agradecer a la Dra. C. Rubinstein (Centro Regional de Investigaciones Científicas y Tecnológicas del Consejo Nacional de Investigaciones Científicas y Tecnológicas de Argentina) por sus determinaciones palinológicas que contribuyeron a precisar la edad de las unidades estudiadas y a la Dra. M. G. Mangano (Universidad de Saskatchewan, Canadá) por su ayuda en las determinaciones icnológicas. Asimismo, hacemos extensivo nuestro agradecimiento a los Dres. L. Buatois (Universidad de Saskatchewan, Canadá), L. Spalletti (Universidad de La Plata, Argentina) y J. Le Roux (Universidad de Chile) árbitros de la revista que ayudaron a mejora la versión última del texto. La Agencia Nacional de Ciencia y Tecnología (Argentina) apoya mediante el Proyecto de Investigación en Ciencia y Tecnología 2000 No. 8920 nuestras investigaciones en el noroeste argentino.

\section{REFERENCIAS}

Albanesi, G.; Astini, R.A. 2002. Faunas de conodontes y Sacabambaspis janvieri (Vertebrata) en el Ordovícico Medio de la Cordillera Oriental argentina: implicancias estratigráficas y paleobiogeográficas. In Congreso Argentino de Paleontología y Bioestratigrafía, No. 8 , Resúmenes: 17. Corrientes.

Allen, J.R.L. 1985. Principles of Physical Sedimentology. Allen \& Unwin: 272 p. Londres.

Angelelli, V. 1946. La Geología del Yacimiento ferrífero de Zapla. Mina 9 de octubre. Revista de la Asociación Geológica Argentina 1: 117-148.

Antelo, B. 1978. Las Formaciones de edad silúrica en el noroeste Argentino, (Provincia de Jujuy y Salta). Revista de la Asociación Geológica Argentina 33 (1): 1-16.

Astini, R.A. 1992. Descripción y génesis de los bancos de oolitas ferruginosas en la base del Silúrico de la Precordillera Argentina. Estudios Geológicos 48: 297-303.

Astini, R.A. 2002. El "horizonte glacial" ordovícico tardío en la Cordillera Oriental y Sierras Subandinas: Paleoambiente sedimentario e implicancias en el análisis de la cuenca del Noroeste argentino. In Reunión
Argentina de Sedimentología, No. 9, Resúmenes: 67 Córdoba.

Astini, R.A. 2003. The Ordovician Proto-Andean Basins. In Ordovician fossils of Argentina (Benedetto, J.L.; editor). Secretaría de Ciencia y Tecnología, Universidad Nacional de Córdoba: 1-74.

Astini, R.A.; Marengo, L. 2003. Sequence Stratigraphy Of Perigondwanic Ordovician Clastics At The Outermost Reach Of The Protoandean Foreland, Sierras Subandinas, Argentina. In Latin American Congress of Sedimentology, No. 3, Extended Abstracts: 116117. Belém, Brasil.

Astini, R.A.; Waisfeld, B.N. 1993. Análisis estratigráfico y paleoambiental del Ordovícico medio (Formación Acoite y Sepulturas) en el borde occidental de la Cordillera Oriental jujeña. In Congreso Geológico Argentino, No. 12 y de Exploraciones de Hidrocarburos, No. 2, I: 96-106. Mendoza.

Astini, R.A.; Marengo, L.; Rubinstein, C.V. 2003. The Ordovician Stratigraphy of the Sierras Subandinas (Subandean Ranges) in northwest Argentina and its bearing on an integrated foreland basin model for the Ordovician of the Central Andean region. In $9^{\text {th }}$ 
International Symposium on the Ordovician System. (Albanesi, G.L.; Beresi, M.S.; Peralta, S.H.; editores), INSUGEO, Serie de Correlación Geológica 17: 381 386.

Astini, R.A.; Waisfeld, B.G.; Toro, B.A.; Benedetto, J.L. 2004. El Paleozoico Inferior y medio de la región de Los Colorados, borde occidental de la Cordillera Oriental (Provincia de Jujuy), Argentina. Revista de la Asociación Geológica Argentina 59 (2): 243-260.

Bahlburg, H. 1990. The Ordovician basin in the Puna of NW Argentina and $\mathrm{N}$ Chile: geodynamic evolution from back-arc to foreland basin. Geotektonische Forschungen 75: 1-107.

Bahlburg, H. 1991. The Ordovician back-arc to foreland successor basin in the Argentinian-Chilean Puna: tectono-sedimentary trends and sea-level changes. In Sedimentation, Tectonics and Eustasy: Processes and Products. (Macdonald, D.I.M; editor). International Association of Sedimentologist, Blackwell Scientific Publications, Special Publication: 465-484. Oxford.

Bahlburg, H.; Furlong, K.P. 1996. Lithospheric modeling of the Ordovician foreland basin in the Puna NW Argentina: On the influence of arc loading on foreland basin formation. Tectonophysics 259: 245-258.

Bayer, U.; Altheimer, F.; Deutschle, W. 1985. Environmental evolution in shallow epicontinental seas: sedimentary cycles and bed formation. In Sedimentary and evolutionary cycles (Bayer, U.; Seilacher, A.; editors). Lecture Notes in Earth Sciences, Springer-Verlag (2): 347-381. Berlín.

Bhattacharya, J.P.; Walker, R.G. 1992. Deltas. In Facies Models: Response to sea Level Change. (Walker, R.G.; James, N.P.; editors). Geological Association of Canada: 157-177.

Benedetto, J.L. 2003. Ordovician fossils of Argentina. Secretaría de Ciencia y Tecnología, Universidad Nacional de Córdoba: 665 p.

Boersma, J.R.; Terwindt, H.J. 1981. Berms on an intertidal shoal: shape and internal structure. International Association of Sedimentologists, Blackwell Scientific Publications, Special Publication 5: 39-49. Oxford.

Bonarelli, G. 1913. Las Sierras Subandinas del Alto de Aguaragüe y los yacimientos petrolíferos del distrito minero de Tartagal, departamento de Orán, provincia de Salta. Anales de la Secretaría de Minería y Agricultura, Sección Geología 8 (4): 1-46.

Bossi, G. E.; Viramonte, J. 1975. Contribución al conocimiento de la petrología de los Yacimientos ferríferos sedimentarios de Zaola y Unchimé. In Congreso Latinoamericano de Geología Económica, No. 5, Actas: 181-202.

Boulton, G.B. 1975. Processes and patterns of subglacial sedimentation. In Ice Ages: Ancient and Moderm. (Wright, A.E.; Mosely, F.; editores). Seel House Press: 7-42. Liverpool.

Boyd, R.; Dalrymple, R.W.;Zaitlin, B.A. 1992. Classification of coastal depositional environments. Sedimentary Geology 80: 139-150.
Bradshaw, M.J.; James; S.J.; Turner, P. 1980. Origin of oolitic ironstones. Discussion. Journal of Sedimentary Petrology 50 (1): 295-304.

Bromley, R.G. 1990. Trace fossils. Biology and Taphonomy. Unwin Hyman: 280 p. Londres.

Brookfield, M.E. 1973. The paleoenvironment of the Abbotsbury Irostone (Upper Jurassic) of Dorset. Paleontology 16: 261-274.

Buatois, L.; Mangano, M.G.; Aceñolaza, F. 2002. Trazas Fósiles. Señales de comportamiento en el Registro Estratigráfico. Museo Paleontológico Egidio Feruglio, Edición Especial 2: $382 \mathrm{p}$.

Buatois, L.; Mangano, M.G.; Malanca, M. 2003. Paleoenvironmental and sequence stratigraphic framework of the Cambrian-Ordovician transition in the Angosto del Moreno area, northwest Argentina. In International Symposium on the Ordovician System No. 9. (Albanesi, G.L.; Beresi, M.S.; Peralta, S.H.; editors), INSUGEO, Serie de Correlación Geológica 17: $397-401$.

Burkhalter, R.T. 1995. Ooidal ironstones and ferruginous microbialites: origin and relation to sequence stratigraphy (Aalenian and Bajocian, Swiss Jura mountains). Sedimentology 42: 57-74.

Cecioni, G. 1949. Informe preliminar sobre el levantamento de la zona Sur del anticlinal de Zapla y parte de Santa Bárbara (Provincia de Jujuy). Instituto Geología y Minería 2 (5): 63-75. Jujuy.

Collin, P.Y.; Loreau, J.P.; Courville, P. 2005. Depositional environments and iron ooid formation in condensed sections (Callovian-Oxfordian, south-eastern Paris basin, France). Sedimentology 52: 969-985.

Collinson J.D.; Thompson, D.B. 1989. Sedimentary Structures. Unwin Hyman Ltd:: 207 p. London.

Cotter, E. 1988. Hierarchy of sea-level cycles in the medial Silurian siliciclastic succession of Pennsylvania. Geology 16: 242-245.

Curray, J.R. 1964. Transgressions and regressions. In Papers in Marine Geology. Shepard Commemorative Volume (Miller, R.L.; editor), Macmillan: 175-203. New York.

Curtis, C.D.; Spears, D.C. 1968. The formation of sedimentary iron minerals. Economic Geology 63: 257-270.

Dalrymple, R.W; Zaitlin, B.A.; Boyd, R. 1992. Estuarine facies models: conceptual basis and stratigraphic implications. Journal of Sedimentary Petrology 62: 1130-1143.

DeCelles, P.G.; Giles, K.A. 1996. Foreland basin systems. Basin Research 8: 105-123.

Deynoux, M. 1985. Terrestrial or waterlain glacial diamictites?. Three case studies from the Late Precambrian and Late Ordovician glacial drifts in West Africa. Palaeogeography, Palaeoclimatology, Palaeoecology 51: 97-141.

Dreimanis, A. 1979. The problem of waterlain tills. En: Moraines and varves (Schlüchter, Ch.; editor). Balkema: 167-177. Rotterdam. 
Droser, M.L. 1991. Ichnofabric of the Paleozoic Skolithos Ichnofacies and the nature and distribution of Skolithos Piperock. Palaios 6: 316-325.

Droser, M.L.; Bottjer, D.J. 1989. Ichnofabric of sandstones deposited in high-energy nearshore environments: measurement and utilization. Palaios 4: 598-604.

Emig, C.C. 1997. Ecology of inarticulated brachiopods. In Treatise of Invertebrate Paleontology (Kaesler, R.L.; editor). Part H. Brachiopoda Revised, Geological Society of America and the University of Kansas Press I: 473-495.

Eyles, N.; Eyles C.H.; Miall, A.D. 1983. Lithofacies types and vertical profile analysis; an alternative approach to the description and environmental interpretation of glacial diamict and diamictite sequences. Sedimentology 30: 393-410.

Eyles, C.H.; Eyles, N.; Miall, A.D. 1985. Models of glaciomarine sedimentation and their application to the interpretation of ancient glacial sequences. Palaeogeography, Palaeoclimatology, Palaeoecology 51: 15-84.

Föllmi, K.B. 1996. The phosphorous cycle, phosphogenesis and marine phosphate-rich deposits. Earth Science Reviews 40: 55-124.

Föllmi, K.B.; Garrison, R.E.; Grimm, K.A. 1991. Stratification in phosphatic sediments: illustrations from the Neogene of California. In Cycles and events in stratigraphy (Einsele, G.; Ricken, W.; Seilacher, A.; editors). Springer-Verlag: 492-507.

Frakes, L.A.; Bolton, B.R. 1984. Origin of manganese grants: sea-level change and anoxic-oxic history. Geology 12: 83-86.

Frey, R.H.; Seilacher, A. 1980. Uniformity in marine invertebrate ichnology. Lethaia 13: 183-207.

Frey, R.H.; Pemberton, S.G. 1984. Trace fossils Facies Models. In Facies Models (Walker R.G.; editor). Geoscience Canada Reprint Series: 189-207.

Frey, R.H.; Pemberton, S.G. 1985. Biogenic structures in outcrops and cores. I. Approaches to ichnology. Bulletin of Canadian Petroleum Geology 33: 72-115.

Gingras, M.K.; MacEachern, J.A.; Pemberton, S.G. 1998. A comparative analysis of the ichnology of wave-and river-dominated allomembers of the Upper Cretaceous Dunvegan Formation. Bulletin of Canadian Petroleum Geology 46: 51-73.

Hagadorn, J.W.; Bottjer D.J. 1997. Wrinkle structures: Microbially mediated sedimentary structures common in subtidal siliciclastic settings at the ProterozoicPhanerozoic transition. Geology 25 (11): 1047-1050.

Hallam, A.; Bradshaw, M. J. 1979. Bituminous shales and oolitic ironstones as indicators of transgressions and regressions. Journal of the Geological Society of London 136: 157-164.

Harrington, H.; Leanza, A. 1957. Ordovician trilobites of Argentina. University of Kansas, Special Publication 1: $276 \mathrm{p}$

Harms, J.C.; Southard, J.B.; Walker, R.G. 1982. Structures and sequences in clastic rocks. Society of Economic
Paleontologists and Mineralogists, Short Course 9: $249 \mathrm{p}$.

Hicock, S.R. 1990. Genetic till prism. Geology 18 (6): 517519.

Ingram, R.L. 1954. Terminology for the thickness of stratification and parting units in sedimentary rocks. Geological Society of America Bulletin 65: 937-938.

Kidwell, S.M.; Fürsich, F.T.; Aigner, T. 1986. Conceptual Framework for the Analysis and Classification of Fossil Concentrations. Palaios 1: 228-238.

Kimberley, M.M. 1979. Origin of Oolitic Iron Formations. Journal of Sedimentary Petrology 49 (1): 111-132.

Kimberley, M.M. 1980. Origin of Oolitic Iron Formations. Reply. Journal of Sedimentary Petrology 50: 299-302

Kley, J. 1996. Transition from basement-involved to thinskinned thrusting in the Cordillera Oriental of southern Bolivia. Tectonics 15 (4): 763-765.

Kley, J.; Gangui, A.; Krüguer, D. 1996. Basement-involved blind thrusting in the eastern Cordillera Oriental, southern Bolivia: evidence from cross-section balancing, gravimetric and magnetotelluric data. Tectonophysics 259: 171-184.

Kreisa, R.D.; Moiola R.J. 1986. Sigmoidal tidal bundles and other tide-generated sedimentary structures of the Curtis Formation, Utah. Geological Society of America Bulletin 97: 381-387.

Mangano, M.G.; Buatois L.A. 1999. Ichnofacies models in Early Paleozoic tide-dominated quartzites: onshore-offshore gradients and the classic Seilacherian paradigm. In International Symposium on the Ordovician System, No. 8, Universitatis Carolinae, Short Papers, Acta 43: 151-154. Prague.

Mangano, M.G.; Buatois L.A. 2003. Trace Fossils. In Ordovician fossils of Argentina (Benedetto, J.L.; editor). Secretaría de Ciencia y Tecnología, Universidad Nacional de Córdoba: 507-553.

MacEachern, J. A.; Pemberton, S.G. 1992a. Stratigraphic applications of the Glossifungites Ichnofacies: Delineating discontinuities in the rock record. In Applications of ichnology to petroleum exploration-A core workshop (Pemberton, S.G.; editor). Society of Economic Paleontologists and Mineralogists, Core Workshop 17: 169-198.

MacEachern, J. A.; Pemberton, S.G. 1992b. Ichnological aspects of Cretaceous shoreface successions and shoreface variability in the Western Interior Seaway of North America. In Applications of ichnology to petroleum exploration-A core workshop (Pemberton, S.G.; editor). Society of Economic Paleontologists and Mineralogists, Core Workshop 17: 57-84.

MacEachern, J. A.; Zaitlin, B.A.; Pemberton, S.G. 1999. A sharp-based sandstone of the Viking Formation, Joffre Field, Alberta, Canada: criteria for recognition of transgressively incised shoreface complexes. Journal of Sedimentary Research, Section B 69: 876 892.

Marengo, L.; Astini, R. 2002. Sedimentología de complejos estuarinos en sectores proximales (Sierra de Zapla) 
de la cuenca ordovícica del noroeste argentino. Reunión Argentina de Sedimentología No. 9, Resúmenes: p. 31. Córdoba.

Monaldi, C.R.; Boso, M.A.; Fernández, J.C. 1986. Estratigrafía del Ordovícico de la Sierra de Zapla, Provincia de Jujuy. Revista de la Asociación Geológica Argentina 41 (1-2): 62-69.

Monteros, J.; Moya, M.C.; Cuerda, A., 1993. Graptolitos Ashgilliano-Llandoverianos en la base de la Formación Lipeón, Sierra de Zapla, Jujuy. Su importancia en la correlación con el Silúrico de la Precordillera Argentina. In Congreso Geológico Argentino No. 12, Actas 2: 304-314.

Nieniewski, A.; Wleklinski, E. 1950. Contribución al conocimiento del anticlinal de Zapla (Provincia de Jujuy). Revista de la Asociación Geológica Argentina 5: 169-203.

Nio, S.D.; Yang, C.S. 1991. Sea level fluctuations and the geometric variability of tide-dominated sand bodies. Sedimentary Geology 70: 161-193.

Pemberton, S.G.; Wightman, D.M. 1992. Ichnological characteristics of brackish water deposits. In Applications of ichnology to petroleum exploration-A core workshop (Pemberton S.G.; editor). Society of Economic Paleontologists and Mineralogists, Core Workshop 17: 141-167.

Pemberton, S.G.; MacEachern, J.A.; Frey, R.W. 1992a. Trace fossils facies models: Environmental and allostratigraphic significance. In Facies models and sea level changes (Walker, R.J.; James, N.P.; editors). Geological Association of Canada: 47-72.

Pemberton, S.G.; Frey, R.W.; Ranger, M.J.; MacEachern, J.A. 1992b. The conceptual framework of ichnology. In Applications of ichnology to petroleum explorationA core workshop (Pemberton, S.G.; editor). Society of Economic Paleontologists and Mineralogists, Core Workshop 17: 1-32.

Pemberton, S.G.; MacEachern, J.A. 1995. The sequence stratigraphic significance of trace fossils: Examples from the Cretaceous foreland basin of Alberta, Canada. In Sequence stratigraphy of foreland basin deposits (Van Wagoner, J.C; Bertram, G.T.; editors). American Association of Petroleum Geologists, Memoir 64: 429-475.

Perlmutter, M.A.; Matthews, M.D. 1992. Global cyclostratigraphy. Enciclopedia of Earth System Science 2: 379-393.

Posamentier, H.W.; Allen, G.P. 1999. Siliciclastic Sequence Stratigraphy. Concepts and Applications. Society of Economic Paleontologists and Mineralogists, Concepts in Sedimentology and Paleontology 7:210 p.

Posamentier, H.W.; Vail, P.R. 1988. Eustatic controls on clastic deposition II-sequence and systems tract models. In Sea level changes-An integrated approach (Wilgus C.K.; Hastings, B.S.; Kendall, C.G.St.C.; Posamentier, H.W.; Ross, C.A.; Van Wagoner, J.C.; editors). Society of Economic Paleontologists and Mineralogists, Special Publication 42: 125-154.
Posamentier, H.W.; Jervey, M.T.; Vail, P.R. 1988. Eustatic controls on clastic deposition I-conceptual framework. In Sea level changes-An integrated approach (Wilgus C.K.; Hastings, B.S.; Kendall, C.G.St.C.; Posamentier, H.W.; Ross, C.A.; Van Wagoner, J.C.; editors). Society of Economic Paleontologists and Mineralogists, Special Publication 42: 110-124.

Postma, G. 1986. Classification for sediment gravity-flow deposits based on flow conditions during sedimentation. Geology 14: 291-294.

Rahmani, R.A. 1988. Estuarine tidal channel and nearshore sedimentation of a Late Cretaceous epicontinental sea, Drumheller, Alberta, Canada. In Tide-influenced sedimentary environments (Boer, P.L.; Van Gelder, A.; Nio, S.D.; editors). Dordrecht, D. Reidle Publishing Company: 433-471.

Ramos, V.A. 1999. Las provincias geológicas del territorio argentino. In Geología Argentina (Caminos, R.; editor), Servicio Geológico Minero Argentino, Anales 29 (3): 41-96.

Rossetti, D.F.; Junior, A.S. 2004. Facies architecture in a tectonically influenced estuarine incised valley fill of Miocene age, northern Brazil. Journal of South American Earth Sciences 17: 267-284.

Rubinstein, C.V. 2003a. Palinomorfos del Ordovícico y Silúrico en el Río Capillas, Sierras Subandinas, Argentina. In Simposio Argentino de Paleobotánica y Palinología No. 12, Abstracts: p. 24.

Rubinstein, C.V. 2003b. Ordovician acritarchs from northwestern Argentina: new insigths into the biostratigraphy and paleoenvironmental aspects of the Central Andean Basin and Famatina. In International Symposium on the Ordovician System No. 9. Ordovician from the Andes (Albanesi, G.L.; Beresi, M.S.; Peralta, S.H.; editors). Instituto Superior de Correlación Geológica 17: 125-130.

Sánchez, T.M.; Marengo, L.A.; Astini, R.A. 2003. Late Ordovician Bivalvia Heteroconchia (Cycloconchidae and Glyptarcidae) from western Argentina. Ameghiniana 40 (3): 433-440.

Schlagintweit, O. 1943. La posición estratigráfica del yacimiento de hierro de Zapla y la difusión del horizonte glacial de Zapla en la Argentina y Bolivia. Sociedad Argentina de Mineralogía y Geología, Revista Minera 13: 155-127.

Seilacher, A. 1964. Sedimentological classification and nomenclature of trace fossils. Sedimentology 3: 256253.

Suárez Soruco, R. 1992. El Paleozoico inferior de Bolivia y Perú. In Paleozoico inferior de Ibero-América (Gutiérrez Marco, J.C.; Saavedra, J.; Rábano, I.; editores). Universidad de Extremadura: 225-239. Mérida.

Suárez Soruco, R.; Benedetto, J.L 1996. Primeros datos sobre la fauna de Braquiópodos de la Formación San Benito en la Cordillera del Tunari, Cochabamba, Bolivia. In Congreso Geológico Boliviano No. 12, 2: 211-216. 
Swift, D.J.P.; Hudelson, P.M.; Brenner, R.L.; Thompson, P. 1987. Shelf construction in a foreland basin: Storm beds, shelf sand bodies, and shelf-slope depositional sequences in the Upper Cretaceous Mesaverde Group, Book Cliffs, Utah. Sedimentology 34: 423-457.

Talbot, M.R. 1974. Ironstones in the Upper Oxfordian of southern England. Sedimentology 21: 433-450.

Tucker, M. 1998. Techniques in Sedimentology. Blackwell Scientific Publications: 394 p. Oxford.

Tucker, M. 2001. Sedimentary Petrology. Blackwell Science, edición No. 3: 262 p. Oxford.

Turner, J.C.M. 1960. Estratigrafía de la Sierra de Santa Victoria y adyacencias. Academia Nacional de Ciencias de Córdoba, Boletín 41, edición No. 3: 262 p.

Tröeng, B.; Claure H.; Olivera, L.; Ballon, R.; Walser, G. 1993. Thematic maps of the minerals resources of Bolivia. Hojas Tarija y Villazón (escala 1:250000). Servicio Geológico de Bolivia, Boletín especial 3: 178 p.

Van Houten, F.B. 1986. Search for Milankovitch patterns among oolitic ironstones. Paleoceanography 1: 459466.

Waisfeld, B.G.; Henry, J.L. 2003. Huemacaspis (Trilobita, Kerfornellinae) from the Late Ordovician of the Argentine Cordillera Oriental. Geobios 36: 491-499.

Watts, A.B. 1989. Lithospheric flexure due to prograding sediment loads: implication for the origin of offlap/ onlap patterns in sedimentary basins. Basin Research 2: $133-144$

Watts, A.B. 2001. Isostacy and flexure of the Lithosphere. Cambridge University Press: 458 p.

Webby, B.D.; Cooper, R.A; Bërgstrom, S.M.; Paris, F. 2004. Stratigraphic framework and time slices. In The Great Ordovician Diversification Events (Webby, B.D.; Paris, F.; Droser, M.L.; Percival, L.G.; editors).Columbia University Press: 41-47.

Wightman, D.M.; Pemberton, S.G.; Singh, C. 1987. Depositional modeling of the Upper Manville (Lower Cretaceous), east-central Alberta: implications for the recognition of brackish water deposits. In Reservoir Sedimentology (Tillman, R.W.; Weber, K.J.; editors). Society of Economic Paleontologists and Mineralogists, Special Publication 40: 189-220.

Zaitlin, B.A.; Dalrymple, R.W.; Boyd, R. 1994. The stratigraphic organization of incised-valley systems associated with relative sea-level changes. In Incised valley systems: origin and sedimentary sequences (Boid, R.; Zaitlin, B.A; Dalrymple, R.; editors). Society of Economic Paleontologists and Mineralogists, Special Publication 51: 45-60. 